\title{
The sedimentary dynamics of Sabellaria alveolata bioconstructions (Ostia, Tyrrhenian Sea, central Italy)
}

\author{
Stefania Nunzia Lisco ${ }^{1}$, Pasquale Acquafredda', Salvatore Gallicchio ${ }^{1}$, Luisa Sabato², Andrea Bonifazi ${ }^{3}$, \\ Frine Cardone ${ }^{2}$, Giuseppe Corriero ${ }^{2}$, Maria Flavia Gravina ${ }^{3}$, Cataldo Pierri ${ }^{2}$ and Massimo Moretti ${ }^{1 *}$ (D)
}

\begin{abstract}
Sabellaria alveolata (Linnaeus 1767) is a polychaete able to build bioconstructions of different thickness, size and patchiness, in intertidal and subtidal environments. Its biological features have been the object of numerous studies worldwide. The worm reefs are formed by millions of tubes built by sand and shells (whole or in fragments) bonded together with a strong glue produced by the worm itself. Hence, Sabellaria alveolata represents a sedimentological asset for the coastal protection, since it contributes to create natural barriers against storm waves and erosion, and supplies the beach with new sandy deposits. This work shows a multidisciplinary approach to studying a bioconstruction of Sabellaria alveolata along the Latium coast (Ostia, Tyrrhenian Sea, central Italy), proposing image analysis as a novel technique to investigate worm reefs, along with classical sedimentological/ ecological tools. The Sabellaria bioconstructions have been analysed at different scales of observation, suggesting the more appropriate strategies to develop a reliable model illustrating the different growth steps of these bioconstructions.
\end{abstract}

Keywords: Sedimentology, Sabellaria alveolata, Bioconstruction, Shallow-marine environment, Image analysis, Tyrrhenian Sea, Latium coast, Ostia

\section{Introduction}

Bioconstructions are fundamental for the conservation of biodiversity on our planet since they favour the creation of complex and heterogeneous habitats. The study of the parameters that regulate reef formation and their persistence is a field of research of great relevance and scientific interest, since it involves the complex interactions between the biosphere and geosphere (Geobiology, sensu Nealson and Ghiorse 2001).

Polychaetes of the genus Sabellaria create large and persistent bioconstructions in shallow-marine environments, especially in temperate water (Naylor and Viles 2000; Fournier 2010 and references therein). Sabellariid worm reefs have been found along the coasts of all oceans and in the Mediterranean Sea. Worm reefs of the genus Phragmatopoma are widespread along the

\footnotetext{
* Correspondence: massimo.moretti@uniba.it

${ }^{1}$ Dipartimento di Scienze della Terra e Geoambientali, Università degli Studi

di Bari, 70124 Bari, Italy

Full list of author information is available at the end of the article
}

American Atlantic coasts (Multer and Milliman 1967; Zale and Merrifield 1989). Along the Pacific coast of America, the presence of sub-tidal reefs built by Sabellaria is reported from North America (Posey et al. 1984), Mexico and Chile (Fournier 2013). Bioconstructions of Sabellariidae polychaetes have also been described from India (Achary 1969, 1974), Malaysia (Ribero and Polgar 2012), and New Zealand (Ekdale and Lewis 1993). Sabellaria alveolata (Linnaeus 1767) and Sabellaria spinulosa (Leukhart 1849) are the most common species along the coasts of northern Europe, locally building massive reefs (Gruet 1986; Holt et al. 1998; Dubois et al. 2003; Braithwaite et al. 2006).

Sabellaria is present in the Mediterranean area with two species: S. alveolata and S. spinulosa. In Italy, scattered mound-shaped reefs and large bioconstructions of S. alveolata occur along the Lazio coast from Circeo to the north of Civitavecchia (Nicoletti et al. 2001), in Liguria along the coast of Genoa (Delbono et al. 2003), and along the south-western Sicilian coast near 
Agrigento and Trapani (Molinier and Picard 1953; Sparla et al. 1992). S. spinulosa is mainly associated with isolated and ephemeral bioconstructions. The only exception in the Mediterranean Sea is represented by the large reef of S. spinulosa, along the northern Gargano coast (Lisco et al. 2017; Gravina et al. 2018).

From an ecological point of view, the role of Sabellaria reefs seems to be very important, because they provide a massive increase in the available space for other species; they also accumulate organic deposits that can be important sources of food for other organisms, thus promoting the increase of local biodiversity (Holt et al. 1998; Pandolfi et al. 1998; Desroy et al. 2011). From a sedimentological point of view, Sabellaria bioconstructions play an important role in the protection of the coasts; indeed, they prevent the erosion of the beach by stabilizing the sediments involved in the bioconstructions (Naylor and Viles 2000). Massive Sabellaria bioconstructions derive from the aggregation of thousands of tubes (Wust 2011; Fournier 2013) that the worm builds by incorporating particles already present in the sedimentary environment (whole sand and/or shell or their fragments) and cementing them together using an adhesive protein that is produced by the worm itself (Gruet et al. 1987). Several papers focus on the particle size range of the sands that the worms such as Sabellaria and Phragmatopoma use to build their bioconstructions. All previous authors studied the grain-size distribution of the sands that are captured by the worms, after mechanically crushing or manually disjointing the bioconstructions samples.

Multer and Milliman (1967; Table 1) already observed that Phragmatopoma lapidosa builds its tubes using sand grains with diameters between $125 \mu \mathrm{m}$ and $500 \mu \mathrm{m}$. Analysing Sabellaria alveolata tubes, Gruet (1984) suggested that the particle dimension in the tubes seems to be mainly conditioned by the building organ size and, subsequently, by the worm age. More recently, many authors (Naylor and Viles 2000 among others) evaluated the grain-size range of the particles that are captured in the tubes of $S$. alveolata, achieved variable results (Table 1) and qualitatively discussed the possibility that composition and morphology of the available sandy grains can play a role during the tube construction.

The aim of this paper is to provide a detailed analysis of textural and mineralogical parameters of Sabellaria alveolata bioconstructions. This study focuses on the Latium coastal area (Ostia, Tyrrhenian Sea, central Italy) where former ecological studies (Taramelli Rivosecchi 1961; Nicoletti et al. 2001; La Porta et al. 2006; La Porta and Nicoletti 2009) reported massive large worm bioconstructions built by this taxon. The largest worm bioconstruction of the Ostia area has been analysed with a multiscale and interdisciplinary approach, using classical ecological and sedimentological monitoring procedures for the evaluation of: (1) the spatial distribution of the worm tubes; (2) the location of sectors with grains that are trapped directly by the worm (tube area) and with grains that are casually located between adjacent tubes (intertube area); (3) the grain-size distribution of sands in tube and intertube areas; (4) the grain size, composition and morphology of sands that are available in the present-day beach environment. The final dataset will enable to establish the textural and mineralogical features of the sands that are directly trapped by the worm.

Furthermore, the structure of the bioconstruction has been investigated without modifying its original morphology analysing, i.e., the relationships between the physical parameters can be quantitatively defined (e.g., the number of worm tubes and the range of tube dimension variability); and, how growth or decline of the worm bioconstruction can be recorded at a microscopic scale. Finally, a general model for the seasonal evolution of the bioconstruction is suggested also considering the role of the worm reefs for the coastal protection.

Table 1 Literature data on sample preparation and granulometric distributions of worm bioconstruction sands

\begin{tabular}{llll}
\hline Authors & Taxa (bioconstruction location) & Sample preparation & Grain-size range \\
\hline Taramelli Rivosecchi (1961) & $\begin{array}{l}\text { Sabellaria alveolata } \\
\text { (Lazio, Italy) }\end{array}$ & $\begin{array}{l}\text { Disaggregation of bioconstruction with a } \\
\text { not-specified method }\end{array}$ \\
Multer and Milliman (1967) & $\begin{array}{l}\text { Phragmatopoma lapidosa } \\
\text { (Florida, America) }\end{array}$ & $\begin{array}{l}\text { Disaggregation of bioconstruction in a } \\
\text { sodium hypochlorite solution }\end{array}$ \\
Gruet (1984) & $\begin{array}{l}\text { Sabellaria alveolata } \\
\text { (France) }\end{array}$ & $\begin{array}{l}\text { Single tubes were individually } \\
\text { disaggregated with hydrogen peroxide } \\
\text { on a hotplate }\end{array}$ \\
Naylor and Viles (2000) & $\begin{array}{l}\text { Sabellaria alveolata } \\
\text { (Great Britain) }\end{array}$ & $\begin{array}{l}\text { Manually separated individual tubes } \\
\text { and disaggregation }\end{array}$ \\
Nicoletti et al. (2001) & $\begin{array}{l}\text { Sabellaria alveolata } \\
\text { (Lazio, Italy) } \\
\text { Sabellaria alveolata } \\
\text { (Liguria, Italy) }\end{array}$ & $\begin{array}{l}\text { Disaggregation of bioconstruction } \\
\text { Delbono et al. (2003) }\end{array}$ & $\begin{array}{l}\text { Disaggregation of bioconstruction with } \\
\text { deionized water washing, automatic } \\
\text { dry sieving }\end{array}$ \\
\hline
\end{tabular}




\section{Geological and geomorphological setting}

Ostia is located along the Latium coastal area (Tyrrhenian Sea), about $30 \mathrm{~km}$ southwest of Rome, central Italy. Late Quaternary morpho-sedimentary evolution of this area is the result of both the complex interaction between tectonic/volcanic processes and sea-level changes and the Tiber delta migration phases (Bellotti et al. 1994; Bellotti et al. 1997; Giraudi 2004; Praturlon 2008; Milli et al. 2013). The present-day Tiber delta area contains a large channel (Fiumara Grande) that flows into the Tyrrhenian Sea at the northwest of the Ostia beach (Fig. 1). An artificial small channel, called Canale dei Pescatori (excavated during the second century AD; Bellotti et al. 1994), flows into the sea a few hundred meters towards the east from the main Sabellaria alveolata bioconstruction, which is the object of this study. From the Fiumara Grande to the Canale dei Pescatori, the Ostia beach shows a longitudinal littoral transport, mainly oriented towards the southeast. The local tidal range is very small $(<0.5 \mathrm{~m})$ and the depth of wave base is about $7 \mathrm{~m}$, being the significant annual wave height of about $4 \mathrm{~m}$ (Ferrante et al. 1993). This sector of the Ostia beach has been deeply modified with interventions (1990 to 2003) of coastal defence and nourishment (Capelli et al. 2007). A submerged barrier runs parallel to the coastline (at a distance of about $150 \mathrm{~m}$ from it) and is placed with base at $-4 \mathrm{~m}$ and crest at $-1.8 \mathrm{~m}$ of water depth. The beach nourishment was carried out in the internal/protected basin using a thick layer of sand and gravel with grain size between $0.08 \mathrm{~mm}$ and $120 \mathrm{~mm}$. Only the upper layer ( $1 \mathrm{~m}$ thick) contains sands with grain size from $0.3 \mathrm{~mm}$ to $1.3 \mathrm{~mm}\left(\mathrm{D}_{50}=0.5 \mathrm{~mm}\right.$; Franco et al. 2004).

\section{Methods}

Field and laboratory procedures are here described following a scale order. Largest-scale monitoring procedures have involved about $20,000 \mathrm{~m}^{2}$ of bioconstruction and adjacent beach sub-environments; smallest-scale measurements have been carried out on the morphometric parameters of single sand grains (with diameters in the order $100 \mu \mathrm{m}$ ).

\subsection{Survey and sampling}

The study area is the Sabellaria alveolata bioconstruction located in the coastal area between "Porto Turistico di Roma" and "Lega Navale" sites (Fig. 1). Surveys and samplings were carried out by scuba diving on seasonal basis during autumn 2013, spring 2014, summer 2014, and winter 2014 (and a qualitative monitoring in autumn 2017). An ecological and sedimentological survey was conducted to define the geometrical parameters of the entire bioconstruction. The ecological monitoring of bioconstructions concerned the evaluation of the relative abundances of both polychaetes and other taxa associated with the bioconstruction, through the comparison of the number of the species that inhabit the rocky bottoms and the sandy ones nearby (Bonifazi et al. 2019). The sedimentological surveys focused on the observation of the physical state of the bioconstructions (area, thickness, depth reached, prevailing morphology, etc.), mainly through detailed underwater photographic documentation (Fig. 2a-d). During the surveys, several sampling campaigns were carried out. Fifteen bioconstruction samples (3 replicates for 5 seasons) were collected, $20 \times$ $20 \times 20 \mathrm{~cm}^{3}$ in size (Fig. 2a), along the central and highest part of the bioconstruction, at different water depths $(1 \mathrm{~m}, 2 \mathrm{~m}$, and $3 \mathrm{~m})$ across different seasons. 4 samples of incoherent sands have been collected at different water depths (between 0 and $5 \mathrm{~m}$ of water depth) along a transect perpendicular to the coastline (Fig. 1). Standard procedures for present-day marine sediments samplings were used (Poppe et al. 2000), collecting 200-400 $\mathrm{g}$ at the water-sediment interface. Finally, in order to investigate the spawning period and to detect the larval peaks in the sea-water, monthly planktonic samples were collected at Marina di San Nicola, about $40 \mathrm{~km}$ north from Rome $\left(41.931^{\circ} \mathrm{N}, 12.110^{\circ} \mathrm{E}\right)$, from April 2015 to March 2016 (April 2015, May 2015, June 2015, July 2015, August 2015, September 2015, October 2015, November 2015, January 2016 and March 2016). These campaigns were carried out near the coastline because Sabellaria larvae are concentrated close to the coast (Dubois et al. 2007). A plankton net, $30 \mathrm{~cm}$ in diameter, circular mouth and $20 \mu \mathrm{m}$ mesh size was used. The net was towed by a scuba diver at a distance of $200 \mathrm{~m}$ from the coastline, maintaining a speed of 1.5 knots $(\sim 0.77$ $\mathrm{m} / \mathrm{s}$ ) and covering a total distance of $1500 \mathrm{~m}$.

\subsection{Laboratory procedures}

The collected samples were frozen immediately after sampling and, later, placed in the oven to dry them before being prepared in the laboratory. Samples used for microscope and image analyses were washed with distilled water and then cemented with epoxy resins. Decimetric slices of this coherent material were obtained to carry out high resolution macrophoto and thin sections for petrographic analyses. High resolution images of the slices, digitized thin sections and microscope photos (at $\times 2.5$ magnification) were used to produce maps of the main structural and textural features of the tubes arrangement. Image $(\odot$, ArcGIS $\odot$, Gradistat $($ ) were used to evaluate size and shape of the grains trapped in the bioconstruction (see below). The procedure of disaggregation of the bioconstruction samples is a difficult operation, but it is necessary to perform standard granulometric analyses. The mechanical breakage of the grains and the friction actions between clasts can create a certain percentage of finegrained particles that are not part of the primary texture. Moreover, the incomplete disaggregation of the tubes 


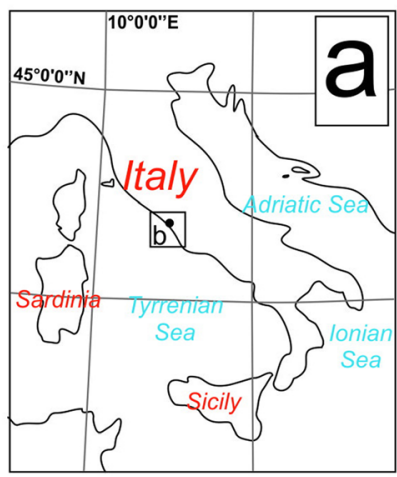

\section{Legend}
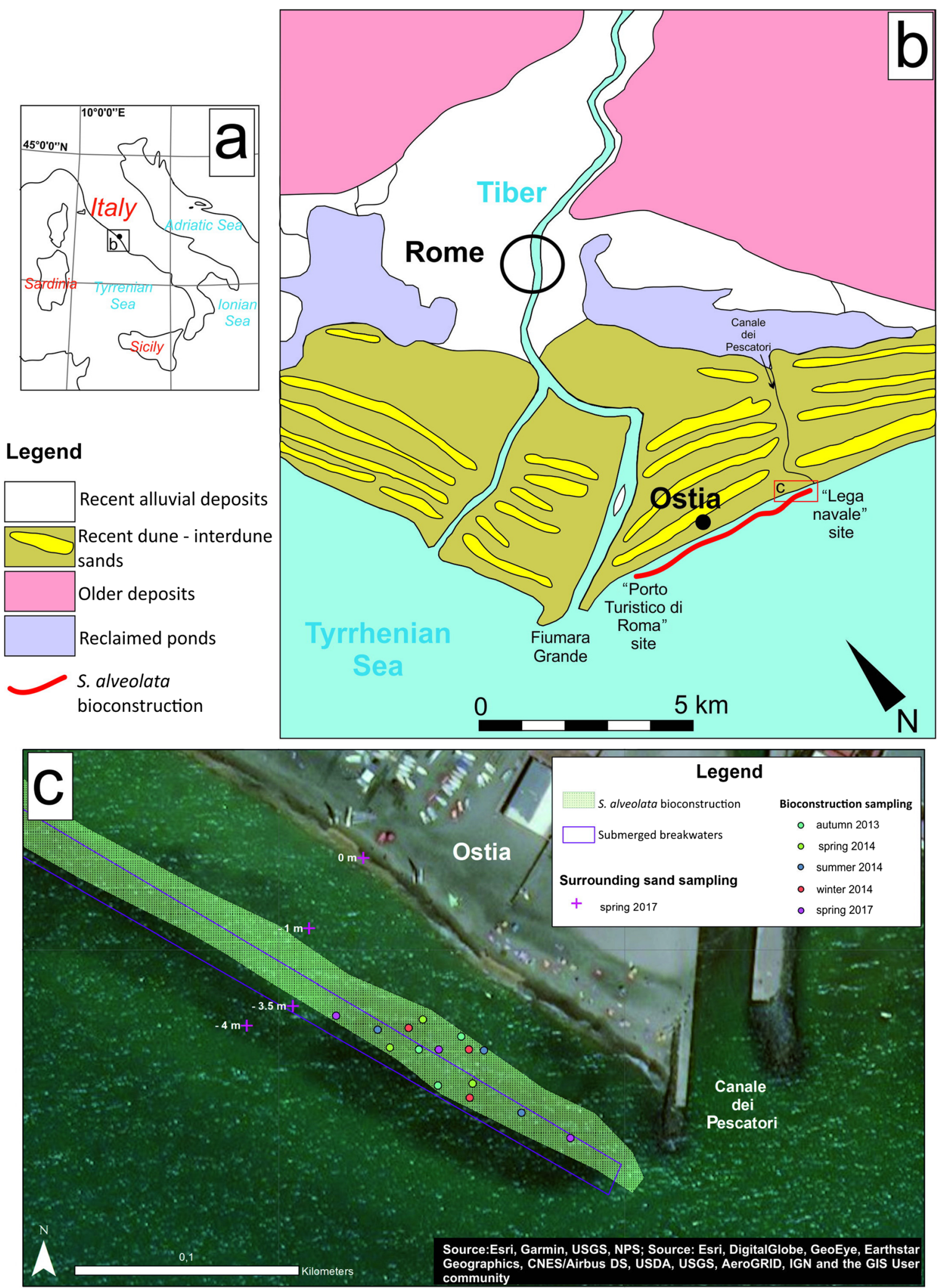

Fig. 1 Maps of the study area. (a) Location of Ostia (Rome, central Italy); (b) Schematic geological map containing main morpho-sedimentary units (modified from Capelli et al. 2007); (c) Detail of the sampling area. The trace of the man-made barrier is reported. Locations of samples of both the bioconstruction and adjacent shoreface sediments are shown 

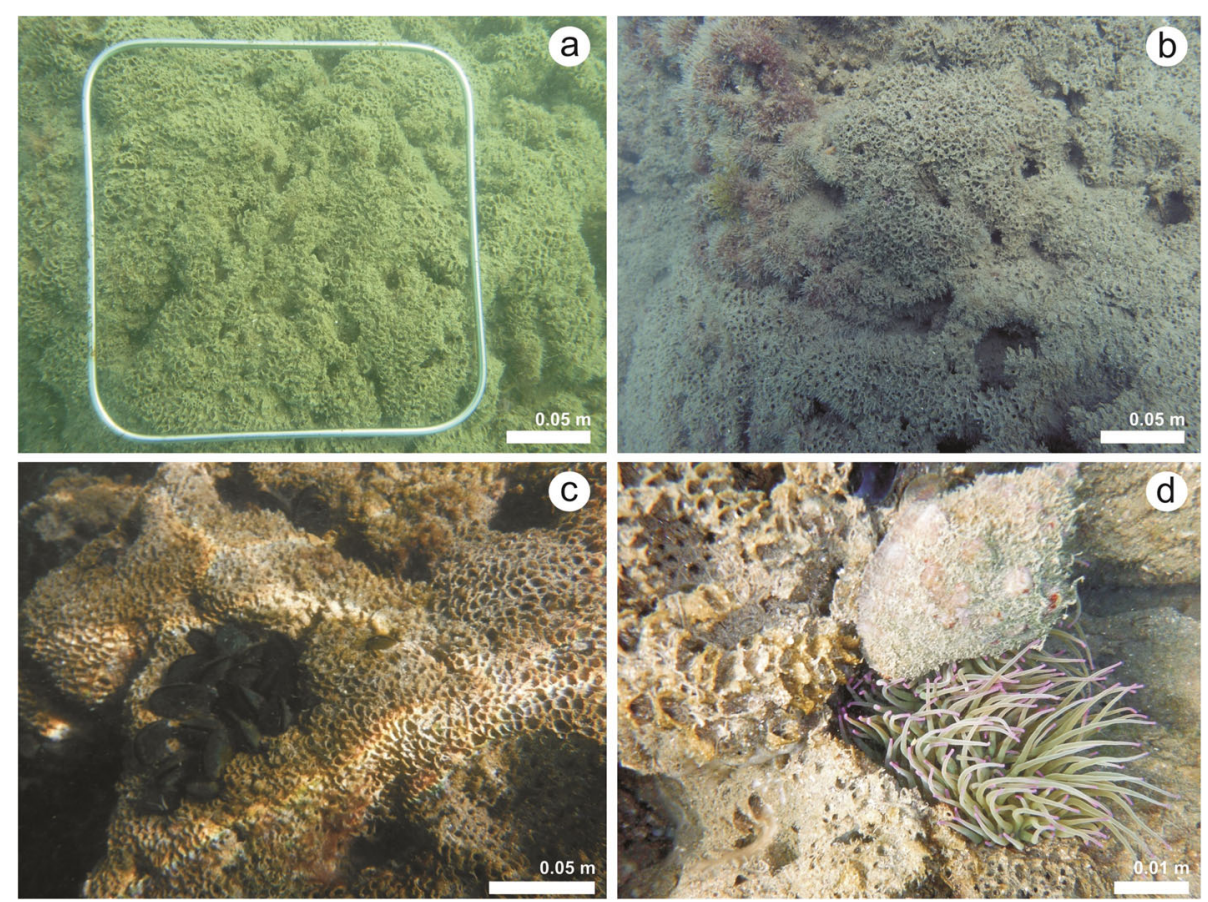

Fig. 2 The Sabellaria alveolata bioconstruction of the Ostia area. (a) September 2013: the morphology of the bioconstruction is irregular; the silver metal frame $\left(20 \times 20 \mathrm{~cm}^{2}\right)$ on the S. alveolata bioconstruction is shown; (b) March 2014: the bioconstruction morphology seems unchanged; (c) June 2014: details of the bioconstruction with sectors of mussel (in black) recruitment; (d) August 2014: details of surfaces that seem to be regularized by erosion (see the top right and bottom left corners of the picture)

causes an increase in the coarse fraction. Samples of $S$. alveolata bioconstructions were disaggregated using a solution of hydrogen peroxide (33\%) in water with proportion of 1 to 4 . This procedure disjoined the individual tubes and eliminated the aggregates of granules, without creating appreciable quantities of fine sediments. Sieving analyses on these incoherent materials were carried out using a $1 / 2$ phi mesh sieve column. Classical petrographic analysis on the bioconstruction was carried out on thin sections at the binocular microscope while the mineralogical composition of beach sands was carried out on the modal class interval counting more than 300 grains for each visual field.

For each sampled block, the density of the worm tubes was measured for ecological analysis purposes, by using a visual estimation technique, counting each tube visible on the sample surface. For the recognition of Sabellaria larvae, all the collected samples were immediately fixed in $10 \%$ neutral buffered formalin, and then the samples were retained through a sieve of $20 \mu \mathrm{m}$ mesh and preserved in $70 \%$ ethanol. Sabellaria larvae were sorted and identified under an optical microscope (Zeiss Axiolab) and counted under a dissecting microscope (Leica WILD M3B).

\subsection{Image analysis procedures}

The analyses of the sedimentological features of the bioconstruction were carried out on samples impregnated with resin to observe the actual structure of the tubes and to distinguish tube and intertube areas. Digital images of the thin sections were scanned using a slide scanner (Polaroid model Spintscan 4000) which is modified to accommodate the glossy thin sections and two polarizing sheets of light. The images under planepolarized light were analysed with Imagej( $\odot$ to calculate the total porosity (the porosity due to the presence of the circular tube voids and the irregular intergranular porosity), density of the tubes and, finally, the diameter variations of the tubes. Classes of diameters were calculated only for sub-circular tubes (Aspect Ratio $=$ major axis/minor axis $<2$ ). After detailed optical microscope analysis aimed to recognize main mineralogical classes, each sand grain has been easily classified in agreement to its size, shape, composition and position within the structure using microscope photos on thin section. ArcGIS $\odot$ maps were used to calculate composition percentages, while the ImageJ৫ facilities were mainly applied to the grain-size distributions and morphometric analyses.

\section{Results}

The results will be shown according to the different scales of observations, from the seasonal monitoring surveys to the microscopic morphometric analysis. This order strictly reflects also the temporal succession of the stages of this study. 


\subsection{Monitoring the bioconstruction: morphology and main ecological features}

The Ostia bioconstruction was measured for the first time during the fall season 2013 (end of September; Fig. 2a). The monitoring analysis focused on a particularly welldeveloped portion of the bioconstruction (Fig. 1c) that extends parallel to the coast between some easily identifiable points. It stands on the crest of the submerged longitudinal barrier and on the interior side of it. Small-scale (0.2 $\mathrm{m}$ in width and $0.1 \mathrm{~m}$ in height) bioconstructions occur in the internal basin and in the open-sea sector and progressively disappear at $4 \mathrm{~m}$ of water depth. On the crest of the barrier, there is a compact bioconstruction that continuously develops parallel to the coastline; in its maximum extension, it reaches more than $3 \mathrm{~m}$ above the sea bottom; its actual thickness is lower being the difference between the man-made barrier height (locally, $2 \mathrm{~m}$ in height). The difficulties related to the recognition of its actual base do not allow a quantitative evaluation of the bioconstruction height, but, where the contact between the bioconstruction and the underlying barrier is visible, its thickness was often more than $1 \mathrm{~m}$.

During the monitoring of early March 2014, the bioconstruction showed no detectable significant changes (Fig. 2b): total area was constant and only the roughness of the bioconstruction morphology appeared slightly increased probably related with newly formed set of tubes.

In June 2014, the bioconstruction showed a slight to moderate degeneration, highlighted by the recruitment of mussels (Fig. 2c). Mussels occupied the localized sectors of the bioconstruction, eroding the bioconstruction but without changing the general morphologies. Furthermore, the contact between the bioconstruction with the underlying coastal defence was more exposed.

The stasis/decline phase in the growth of the bioconstruction remained unchanged even in early August 2014 (Fig. 2d). The sectors with flat-regularized surfaces in the bioconstruction and areas of man-made barrier without a bioconstruction cover were widespread but the sectors with mussels seemed unchanged.

The last monitoring had been carried out during the autumn of 2017 in order to verify the persistence of the bioconstruction after 3 years and to qualitatively describe the bioconstruction but without sampling. The survey showed a bioconstruction that is growing again, covering the whole submerged barrier, in a continuous and compact way, with large hummocks and rough mounds (Fig. 3).

Mean values of the Sabellaria tube density measured on samples from the surveys of years 2013-2014 using the visual counting technique are shown in Table 2. The highest tube density value was measured in August 2014 with $34,800 \pm 1100$ tubes $/ \mathrm{m}^{2}$; conversely, the lowest tube density value was measured in September 2013 with 21, $450 \pm 800 \mathrm{tubes} / \mathrm{m}^{2}$.

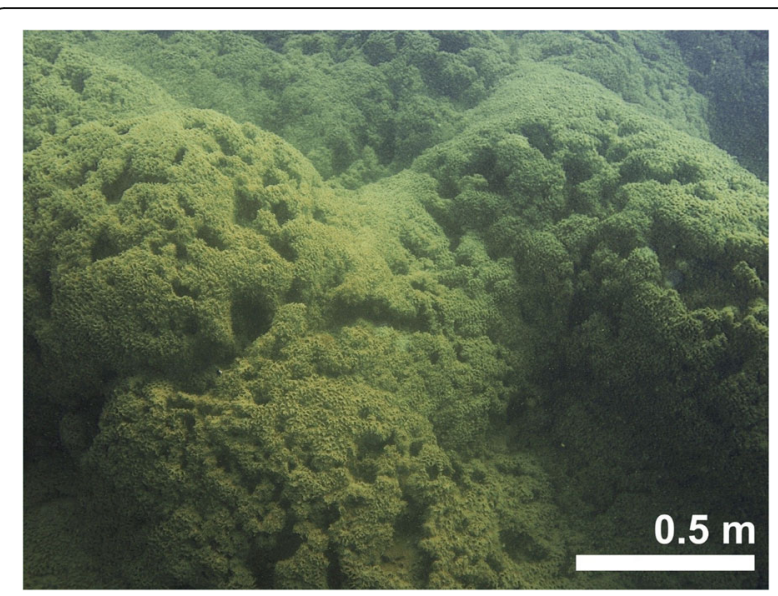

Fig. 3 The Sabellaria alveolata bioconstruction of the Ostia area in November 2017. The complex and irregular morphology is typical of the growth stages

Plankton samples collected from April 2015 to March 2016 showed large variations in larval abundance throughout the year, even though Sabellaria larvae were detected in all monthly surveys. The number of Sabellaria larvae showed an increase from late spring to summer months; however, the larval peak was identified during the autumn months, from early October to late November (Fig. 4).

\subsection{Image analysis on the bioconstruction samples}

The evolution of the structure of the Ostia Sabellaria alveolata bioconstruction over time can be easily defined using qualitative description, mainly related to the morphology of the bioconstruction. Nevertheless, by a rigorous geometric point of view, the changes in the large-scale morphology of the bioconstruction are very complex to describe. To overcome this difficulty, in this study, the measurement of some simple small-scale descriptor parameters (tube density, variability of the tube diameter, porosity) is taken as a record of seasonal changes in the bioconstruction.

\subsubsection{The density of the tubes}

The density value is here defined as the number of tubes/unit area calculated on thin sections (about 8 $\mathrm{cm}^{2} \times 16$ fields) of the bioconstruction (Fig. 5). The density values measured in this way vary seasonally. The average value is approximately 83,000 tubes $/ \mathrm{m}^{2}$ with a range varying from $157,100 \pm 42,000$ tubes $/ \mathrm{m}^{2}$ in autumn to $43,000 \pm 14,600$ tubes $/ \mathrm{m}^{2}$ in winter (Fig. 6). The number of tubes is very high in the autumn samples, but it is quite constant during other seasons (the differences are equal to the standard deviation). The seasonal significance of the number of tubes per unit area $\left(/ \mathrm{m}^{2}\right)$ is obviously not univocal and the tube diameters and their 
Table 2 Density of the Sabellaria tubes at each sampling date obtained by (1) using a visual counting technique; and, (2) evaluating in thin sections

\begin{tabular}{lll}
\hline Sampling date & $\begin{array}{l}\text { The Sabellaria tube } \\
\text { density }(1)\left(\text { tubes } / \mathrm{m}^{2}\right)\end{array}$ & $\begin{array}{l}\text { The Sabellaria tube } \\
\text { density }(2)\left(\text { tubes } / \mathrm{m}^{2}\right)\end{array}$ \\
\hline September 2013 & $21,450 \pm 800$ & $157,100 \pm 42,000$ \\
March 2014 & $28,325 \pm 900$ & $43,000 \pm 14,600$ \\
June 2014 & $24,500 \pm 900$ & $61,000 \pm 7200$ \\
August 2014 & $34,800 \pm 1100$ & $71,600 \pm 5300$ \\
\hline
\end{tabular}

variability need to be considered as well. Discrepancies between density values obtained with different methods are treated in the "Discussion" section.

\subsubsection{The variability of tube diameters}

The worm tube dimensions measured on a large number of thin sections are very variable (Fig. 5). Nevertheless, this variability seems to follow simple regularities with the succession of the seasons (Fig. 6). Maximum diameters are recorded in March 2014 (about $5300 \mu \mathrm{m}$ ) while they are constant in the other seasons (about $3000 \mu \mathrm{m})$. In September 2013 and March 2014, the classes of small diameter appear frequently. Minimum and mean diameters gradually and regularly increase from September 2013 to August 2014. The range of the different classes of diameters seems to be seasonallyinfluenced too (Fig. 6): this range is high in March 2014 $(\sim 170 \mu \mathrm{m}<\mathrm{d}<\sim 5300 \mu \mathrm{m})$, and low in August 2014 ( $820 \mu \mathrm{m}<\mathrm{d}<\sim 3100 \mu \mathrm{m})$.

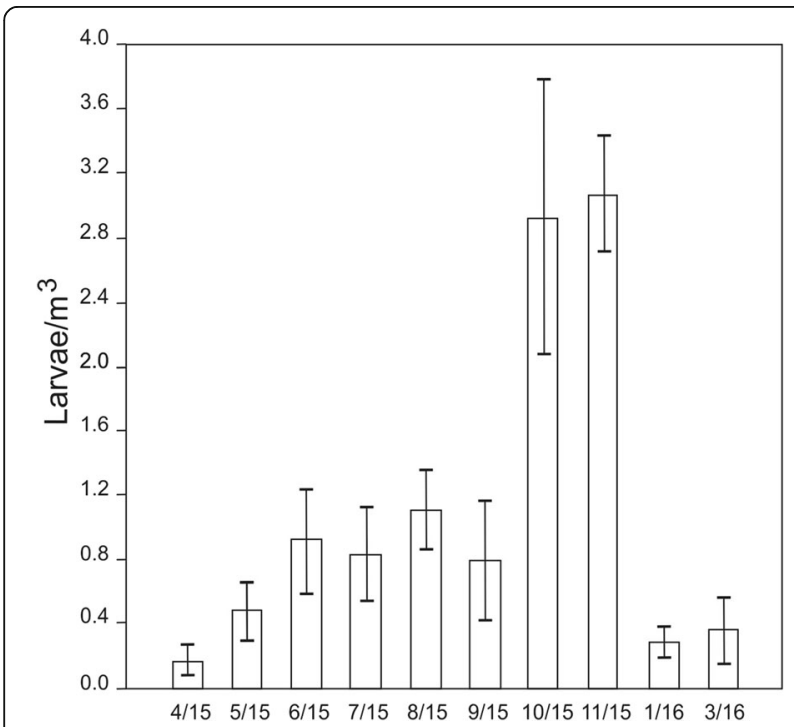

Fig. 4 Bar chart showing the monthly mean number of Sabellaria larvae per $\mathrm{m}^{3}$ of water. 4/15 means April 2015; 3/16 stands for March 2016

\subsubsection{Porosity}

The measure of the porosity $\left(n=V_{v} / V_{T}\right.$, i.e. void volume/sample volume) was performed on the highresolution photos of the decimetric (impregnated and glossy) slices of the bioconstruction samples. The porosity is calculated by ImageJ $\odot$ for the grey levels related with the resin color. Therefore, these values indicate the total porosity of the bioconstruction (sum of the voids occupied by the worm, the intergranular and intragranular porosity) and vary from $28 \%$ to $37 \%$, without recording a regular seasonal variability.

\subsection{The microstructure of the worm tubes}

Analysing the structure of the bioconstruction in more detail (Fig. 7), it is always possible to recognize the empty circular void that represents the area occupied by the worm when it was alive. The variability of this void has been discussed in the previous section. The grains closest to the void (tube) appear to be placed around it, with a surprising regular tangential order (Fig. 7). Outside the tube (intertube), sand grains are arranged in a more chaotic way.

These two different areas can be distinguished in all samples (Fig. 8). Often, the distinction between tube and intertube sectors can be confirmed observing the sudden changes in grain size too (Fig. 8a). Locally, it is possible to recognize sets of tubes characterized by very small diameters (between $200 \mu \mathrm{m}$ and $400 \mu \mathrm{m}$ ), with a regularlyspaced structure that repeats itself in space (Fig. 8b). The tube area is reduced to a single thin layer composed of about 15-20 sand grains. In the thin sections that are parallel to the general development of the tubes, the area occupied by the worm is clearly recognisable as a linear feature; it is limited by grains oriented parallel to the tube wall. In areas not far from the tube, the grain size appears to increase rapidly and, here, no preferential orientation is observed (Fig. 8c). Textural analyses under the microscope show that the general structure of the bioconstruction is influenced by the tube growth. Tubes grow next to each other and form a grossly ordered and porous structure that can include also the sand of intertube area.

The internal part of some tubes can be filled by sands (Fig. 9). The number of these filled tubes is always very low. There is not a remarkable variation of their occurrence in different seasons. September 2013 and March 2014 contain the lowest number of filled tubes ( 2 in each season) while June 2014 and August 2014 have 3 and 5 filled tubes respectively.

\subsubsection{Textural analyses}

Diameters of particles that form the tube and intertube sectors allow them to obtain an indirect granulometric distribution for each part of the bioconstruction (Fig. 10). 


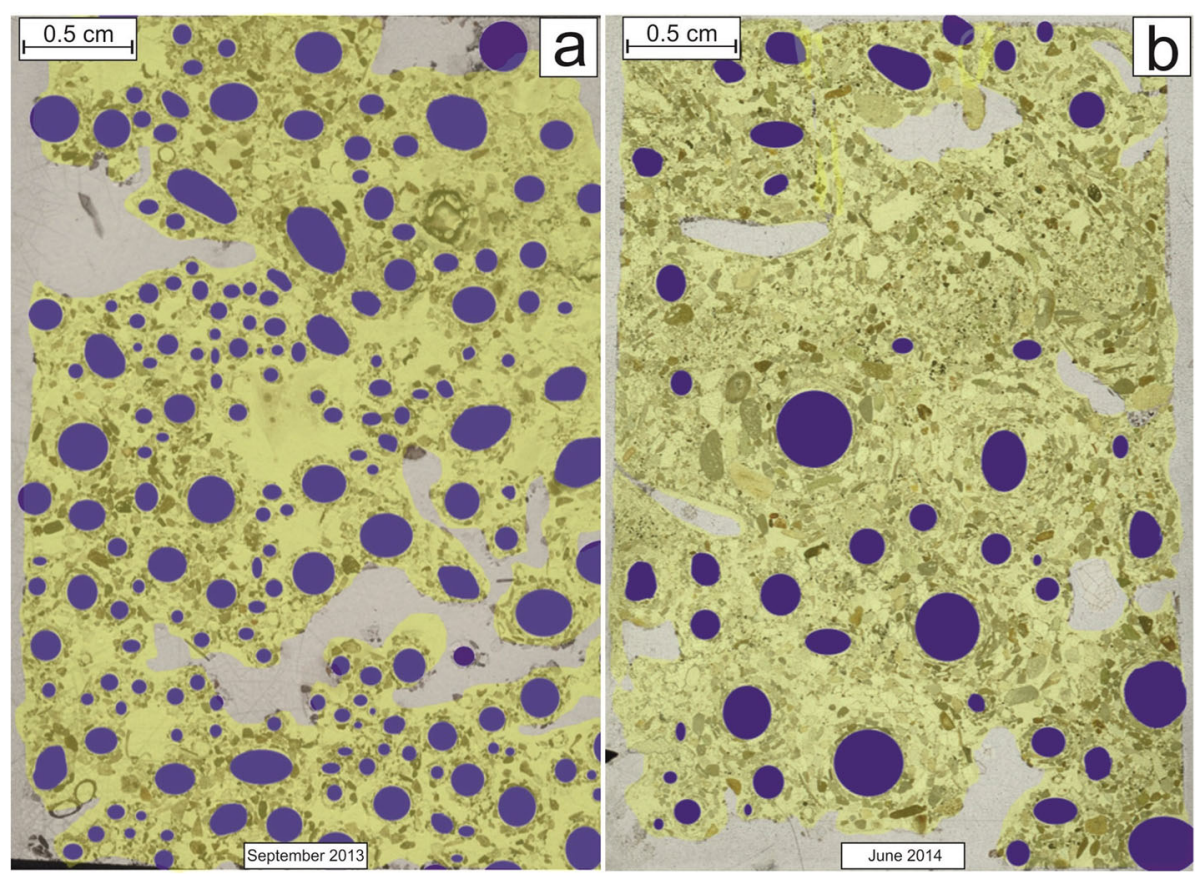

Fig. 5 Examples of digitized thin sections elaborated in ImageJ@ software. The number of worm tubes can be easily evaluated. Note the tube dimension variability in different seasonal samples (a - September 2013; b-June 2014)

The range of the granulometric distribution seems to be reliable. The sands located between adjacent tubes (intertube) seem to be less sorted in grain size than the sands directly trapped by the worm (tube). Nevertheless, the fiftieth percentile of the grain-size distribution $\left(D_{50}\right)$ has the same dimension in the two sectors, being $D_{50}=$ $207 \pm 48 \mu \mathrm{m}$ in the tubes and $D_{50}=204 \pm 37 \mu \mathrm{m}$ in the intertube sectors.

The grain-size analysis carried out by physically sieving the sand samples collected from different water depths $(0.0 \mathrm{~m},-1.5 \mathrm{~m},-3.5 \mathrm{~m}$, and $-5.0 \mathrm{~m})$ are shown in Fig. 11a. The $D_{50}$ is variable, slightly varying between $311 \mu \mathrm{m}$ and $499 \mu \mathrm{m}$, but is always higher than the fiftieth percentile of the sediment distribution that is trapped in the worm tubes (about $200 \mu \mathrm{m}$ ). The distribution is always unimodal. Sorting is related to moderately classified sand. The value of Kurtosis indicates a leptokurtic distribution. Skewness values are generally close to zero and therefore approximately symmetric, with the exception of the sample collected at $1.5 \mathrm{~m}$ depth, tail towards coarse sediments, where the Skewness value is instead negative.

The physical grain-size analyses were carried out also on 3 bioconstruction samples taken at $2 \mathrm{~m}$ of water depth after complete disaggregation procedures (Fig. 11b). The sediments have a $\mathrm{D}_{50}$ that is slightly variable between $241 \mu \mathrm{m}$ and $332 \mu \mathrm{m}$. The distribution is unimodal only for one sample (O1-OS_14C in Fig. 11b). Sorting corresponds to moderately classified sand; the value of Kurtosis indicates a mesokurtic distribution; the Skewness value is close to zero (symmetric Sk). For the other two samples (O2-OS_14C and O3-OS_14C), the distribution is mainly bimodal, and therefore, the statistical parameters cannot be considered representative.

The morphometric analyses of the bioconstruction sands have been conducted to quantitatively compare the shape of the grains of the tube and intertube (Fig. 12). The mean value of Aspect Ratio measured in the tube grains is always slightly higher than in the intertube sands $(2.37 \pm 0.54$ for the tube and $1.94 \pm 0.20$ for the intertube; Fig. 13a). The mean Circularity value calculated on the grains composing the tubes is $0.64 \pm 0.05$ while the grains of the intertube areas have a mean Circularity value of $0.67 \pm 0.05$ (Fig. 13b).

\subsubsection{Compositional analyses}

To compare the minerals that form the tube and the intertube sectors of the bioconstruction with those that are available in the surrounding beachface and shoreface environments, their composition has been established using a quantitative approach.

The main mineral phases of sands trapped in the bioconstruction have been recognised in thin section (Fig. 14). The lithic fragments are very abundant and mainly derive from the erosion of metamorphic and effusive magmatic rocks (rhyolites); lithoclasts of micritic limestones have been recognised too. Quartz is very abundant and is present as crystalline quartz, 

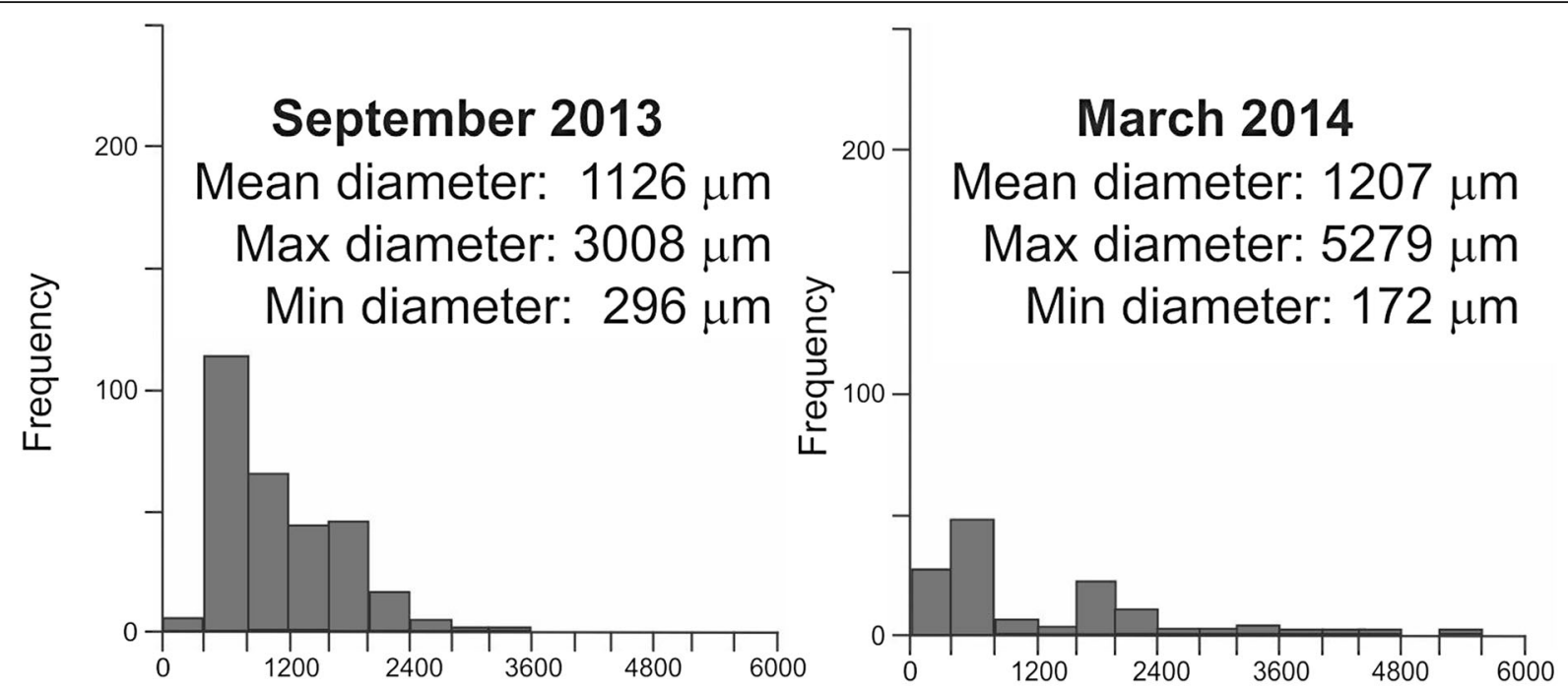

Distribution intervals of the diameters $(\mu \mathrm{m})$

\begin{tabular}{|c|c|c|}
\hline Autumn & Area $\mathrm{cm}^{2}$ & $\mathrm{~N}^{\circ}$ of tubes \\
\hline $\mathrm{AO} 1$ & 1 & 11.02 \\
$\mathrm{AO} 2$ & 1 & 21.29 \\
$\mathrm{AO} 3$ & 1 & 17.67 \\
$\mathrm{AO} 4$ & 1 & 16.57 \\
$\mathrm{AO} 5$ & 1 & 12.02 \\
Mean value & $1 \mathrm{~cm}^{2}$ & 15.71 \\
\hline
\end{tabular}

Distribution intervals of the diameters $(\mu \mathrm{m})$

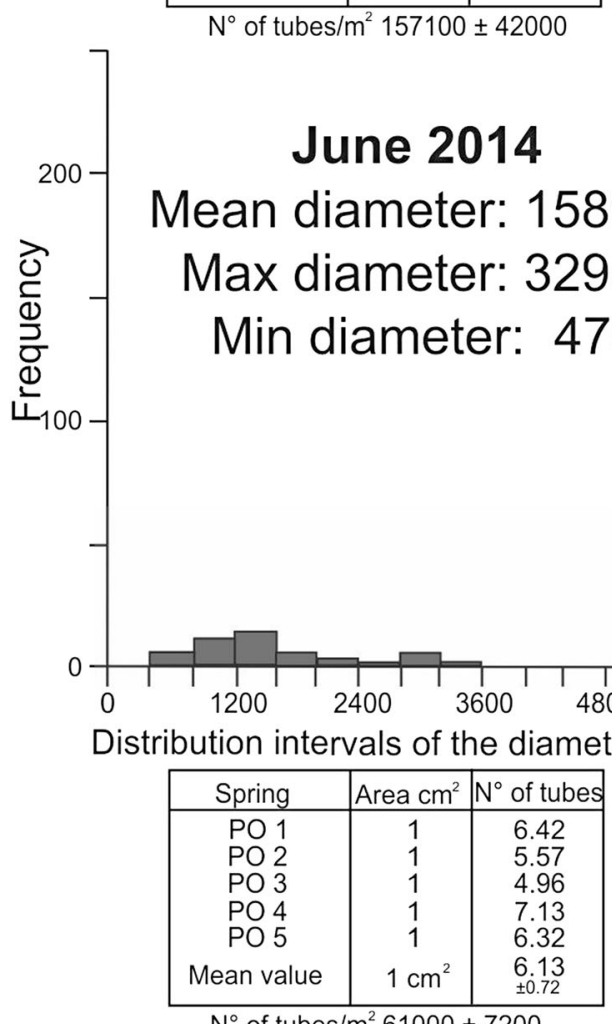

\begin{tabular}{|c|c|c|}
\hline Winter & Area $\mathrm{cm}^{2}$ & $\mathrm{~N}^{\circ}$ of tubes \\
\hline IO 1 & 1 & 4.96 \\
IO 2 & 1 & 3.67 \\
IO 3 & 1 & 3.49 \\
IO 4 & 1 & 2.87 \\
IO 5 & 1 & 6.55 \\
Mean value & $1 \mathrm{~cm}^{2}$ & 4.21 \\
\pm 1.46 \\
\hline
\end{tabular}

$\mathrm{N}^{\circ}$ of tubes $/ \mathrm{m}^{2} 43000 \pm 14^{\prime} 600$

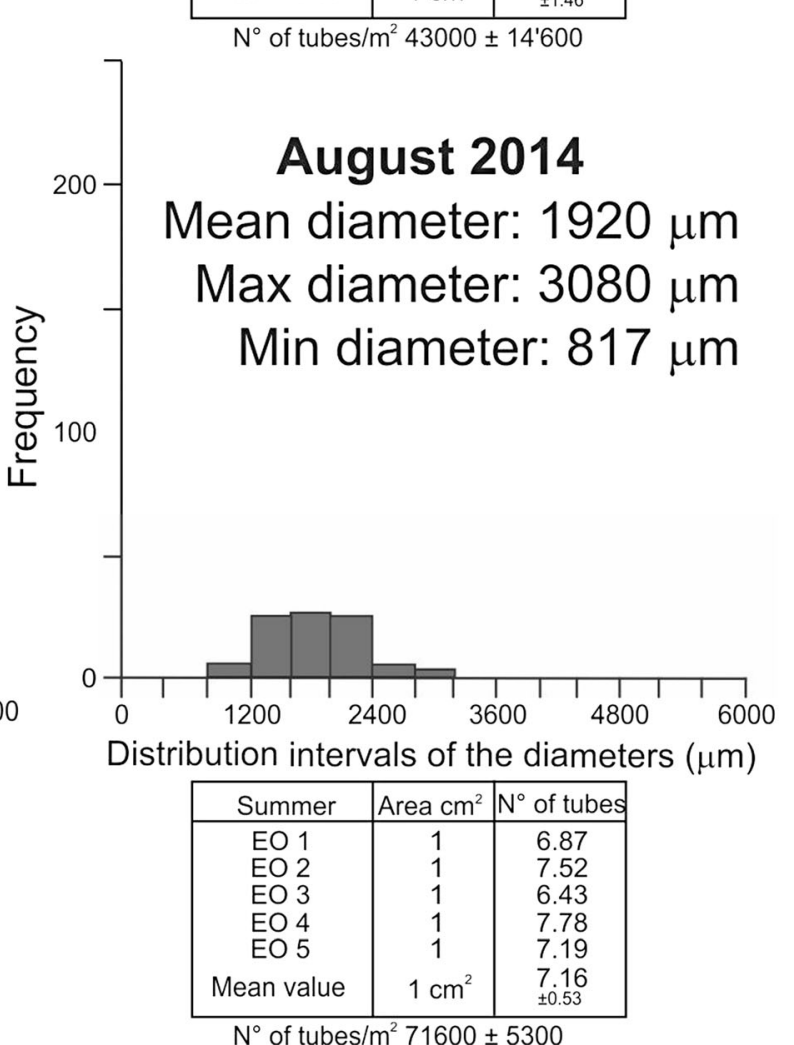

Fig. 6 Diameter classes histograms of worm tubes measured in thin section with Imagej@ software. Density of tubes is shown. Maximum diameters are recorded in March 2014. In September 2013 and March 2014, many tubes with small diameters occur. Minimum and mean diameter of the worm tubes continuously increase from September 2013 to August 2014. The greatest/largest difference between maximum and minimum diameter is recorded in March 2014 while the least/lowest difference occurs in August 2014. The column showing the name of the season contains the list of the five sample areas for each seasonal sampling set with the abbreviations: AO1, AO2, etc. 


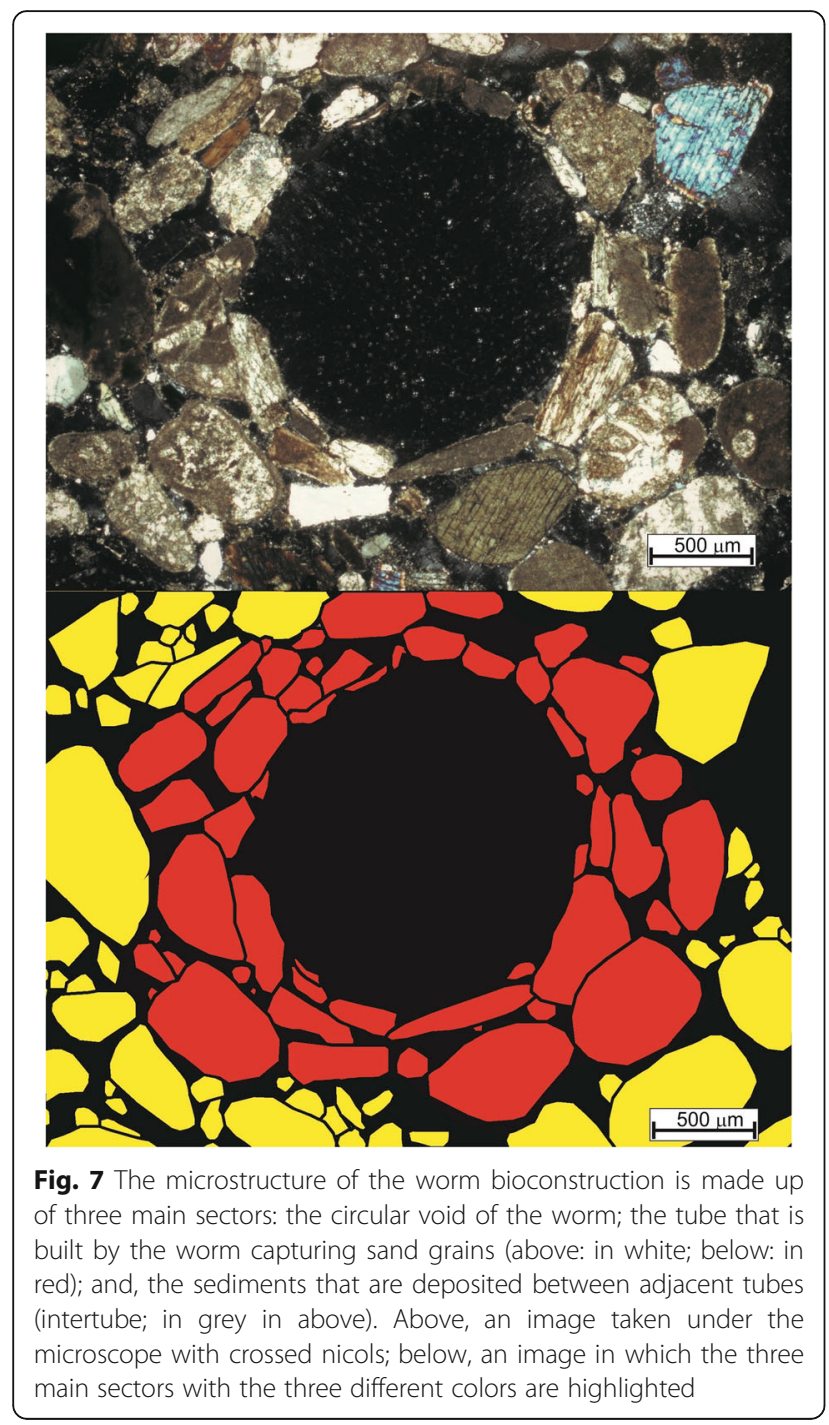

polycrystalline, flint and chalcedony. Feldspars are represented by both potassium feldspars and plagioclases. Plagioclases sometimes appear to be heavily seriticized, while potassium feldspars can occur in the form of a microcline with perthitic mixing. Amphiboles with the diopsidic composition, pyroxenes with pleochroism in shades of green, and micas are observed among the colored minerals. Finally, carbonate bioclasts are abundant too. They occur both as entire (foraminifera) and in fragments (mainly molluscs and sea urchin spines). Many serpulid tubes have been recognised.

The mineralogical composition has been obtained by classifying sands on microscope high-resolution images of thin sections. Compositional maps have been compiled distinguishing tube and intertube sectors (Fig. 15).

The petrographic and mineralogical characterization of the beach sands has been carried out with a stereo microscope on the modal class interval $(125-500 \mu \mathrm{m})$. The sands coming from the beachface and shoreface contain the same mineral phases of the sands that are trapped in the bioconstruction. Counting more than 300 grains in every observation field, a quantitative modal composition of these sands has been obtained.

The composition of tube or intertube bioconstruction and beach sands has been compared using the classical Folk (1974) triangular diagram. In agreement to this classification, all sands are defined as lithic arenites and there is no obvious difference between the composition of sands that are trapped by the worm in the tube, or that are located between adjacent tubes, or that are available in the sedimentary environment.

\section{Discussion}

The discussion of results focuses on three main topics that are interconnected at various temporal and spatial scales: (1) the origin of seasonal phases of the bioconstruction; (2) how the textural features of the bioconstruction can record these changes; (3) the significance of mineralogical features of the sands that form the worm bioconstruction. These aspects are discussed following a scale-dependent order.

\subsection{Record of seasonal changes of the Sabellaria alveolata bioconstruction}

The monitoring survey of one of the most impressive worm bioconstructions of the Latium coast shows that it is subjected to seasonal phases of growth (autumn and winter) and stasis (spring and summer) that alternate leaving the bioconstruction in general good conditions (Figs. 2 and 3). It is very challenging to seasonally measure the dimension of the bioconstruction since it develops on a man-made barrier. The state of the bioconstruction can be better monitored by qualitatively describing the roughness of main hummocks and mounds. To verify these observations in a more quantitative way, samples of bioconstruction have been collected and analysed from an ecological and sedimentological point of view. The number of tubes has been evaluated with two simple methods (Table 2): (1) by visual counting and (2) in thin sections under a binocular microscope. Obviously, the microscopic analysis leads to a more accurate evaluation for the tube number allowing an easier recognition of small tubes.

Many procedures for the calculation of the tube density are based on the visual counting methods carried out in laboratory or even with ROV (Remotely Operated Vehicle) observations (Gubbay 2007). This kind of procedure can induce errors also in the interpretation of growth and stasis stages: in thin section, the maximum number of tubes corresponds to September 2013, while the visual counting recognizes a minimum number of tubes in the same month. For the ecological approaches, the value of density is related to the number of living worms in a given volume of the bioconstruction. 


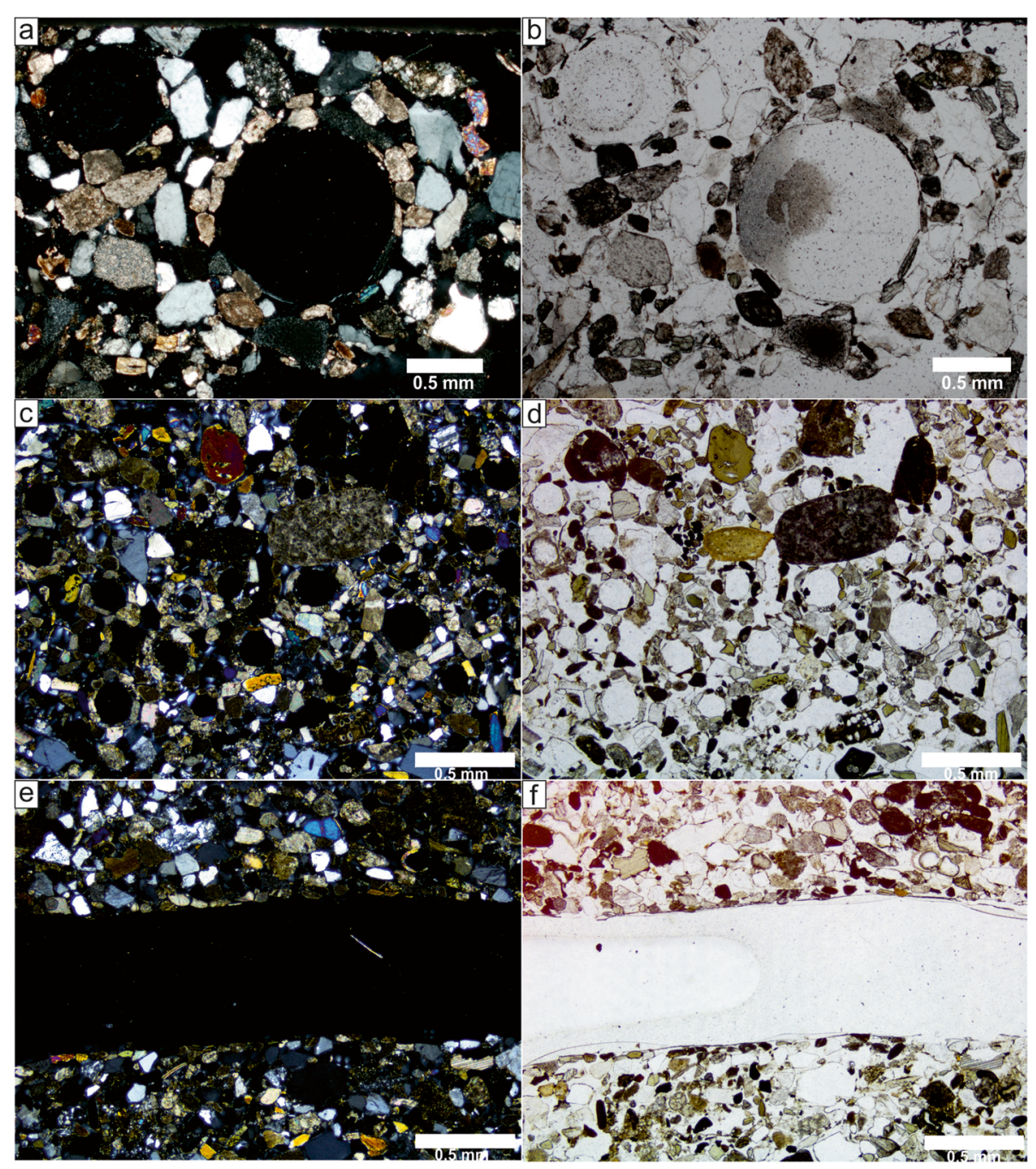

Fig. 8 Microstructures of the Sabellaria alveolata bioconstruction in plane-polarized light photos $(\mathbf{a}, \mathbf{c}, \mathbf{e})$ and between crossed-polarized photos $(\mathbf{b}, \mathbf{d}, \mathbf{f})$. The internal part of the worm tubes (in white) has been redrawn. $(\mathbf{a}, \mathbf{b})$ Two tubes with different diameters. Note the increase of the grain size outside the tube; $(\mathbf{c}, \mathbf{d})$ Sets of small-scale worm tubes. Tube grains are very fine-grained; (e, $\mathbf{f})$ Cross-section of a tube in a plane parallel to its vertical development. Note the perfect alignment of elongated grains along the tube wall
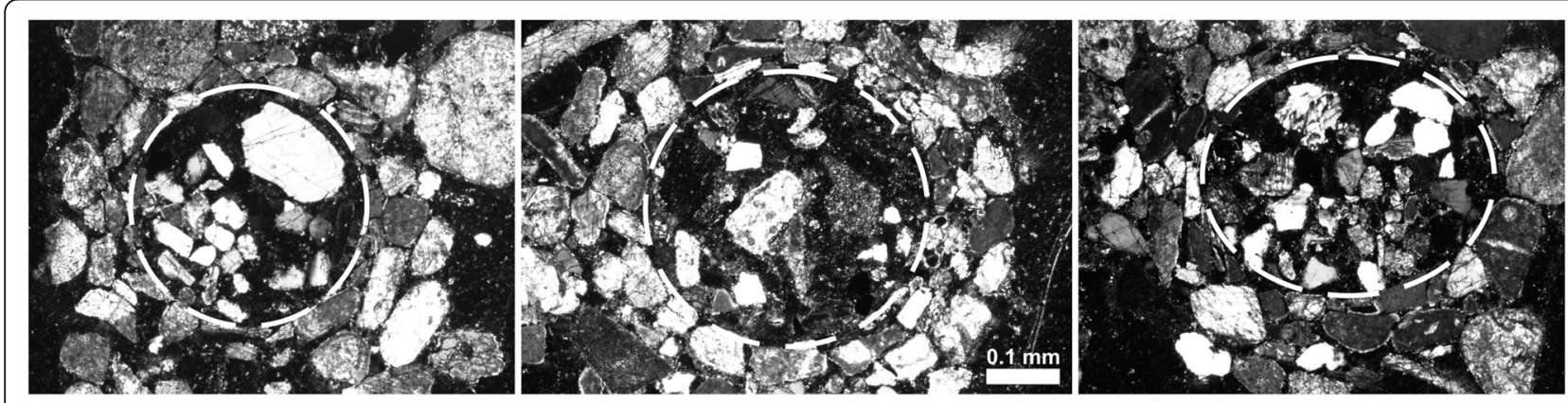

Fig. 9 Three examples $(\mathbf{a}-\mathbf{c})$ of worm tubes filled by sands. The dotted white circle represents the internal wall. The scale is the same in all photos 


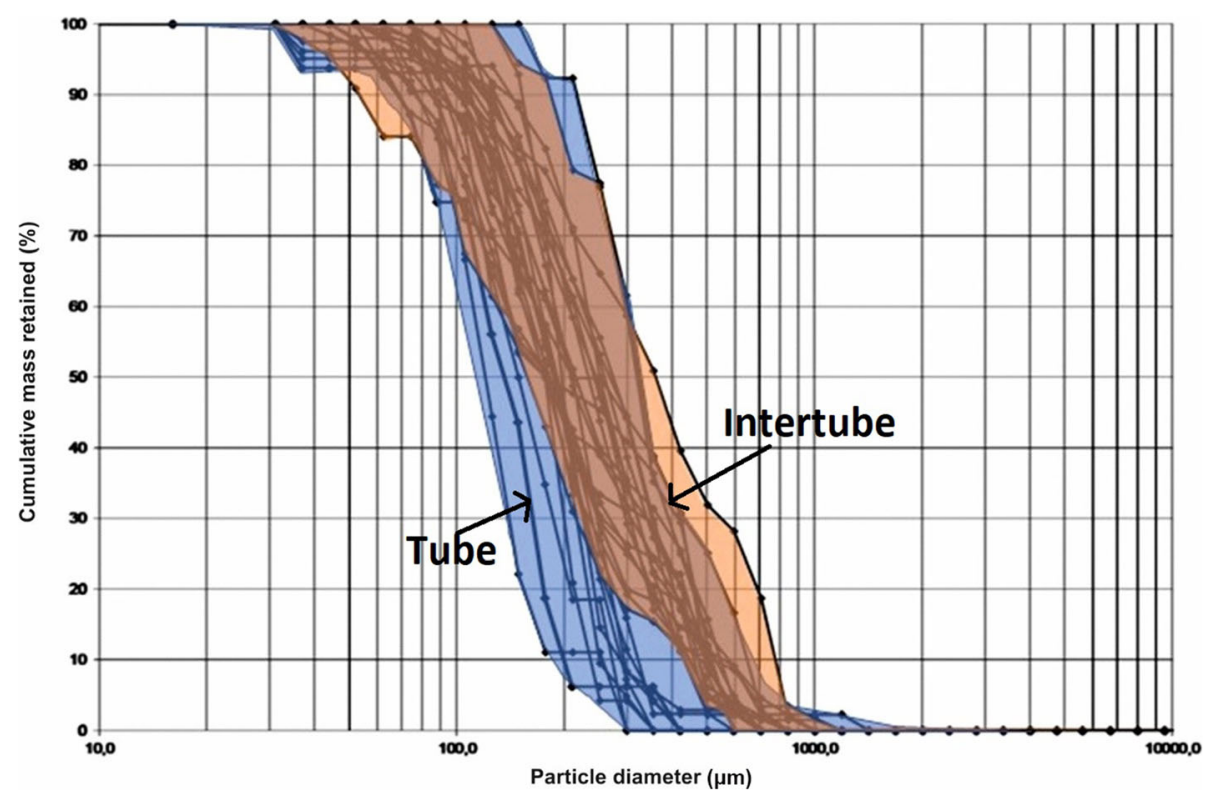

Fig. 10 Image analysis for the granulometric distribution of the bioconstruction sediments. In blue, the range of the grain-size cumulative curves of the tube sectors was derived; in brown, the range of the grain-size cumulative curves of sediments forming the intertube sectors of the bioconstruction was derived. Note that they occupied different fields of the granulometric distribution even if $D_{50}$ was the same

However, this data is not directly related with the physical parameters of the bioconstruction (volume, porosity, number of tubes, etc.) that are the focus of this study.

The density of tubes (number of tubes in a given area) is strongly dependent from their dimensions. Moreover, the tube dimensions (the diameter of the circular void occupied by the worm) in different seasons have been accurately measured (Fig. 6). These data are interesting, since they record the effective recruitment stages of the Sabellaria alveolata bioconstruction: young worms are associated with small tubes and the old ones occupy large tubes. A large variability of the tube dimensions is associated with the growth periods of the bioconstruction (autumn and winter) that are characterized by the abundance of small-diameter tubes (young individuals). A narrow range of diameter variability and the abundance of large diameters are records of a stasis stage of the bioconstruction (spring and summer). Young individuals regularly grow from autumn to summer and this process is recorded by the continuous increase of minimum and mean diameters from September 2013 to August 2014 (Fig. 6). Older individuals live in the largest measured tubes (more than $5 \mathrm{~mm}$ in diameter), and these dimensions are also the maximum diameters reported in the literature (Fournier 2013). It means that these individuals survived to some seasonal changes of different years, because 4-5 years is the average life span of these worms (Gruet 1984).
This interpretation is supported by the Sabellaria larvae monitoring data. The larval peak measured in this area occurs from early October to late November (Fig. 4) even if the presence of larvae at different development stages for most of the year, including the early trochophore, suggests a protracted spawning season. These results are in partial accordance with those of Gruet and Lassus (1983) and Dubois et al. (2007) reported along the Northern Atlantic coasts: these authors observed two distinct different periods of high larval density, in April and from early September to early October.

The data suggest that the growth and stasis stages are not related with fixed seasonal spawning periods. On the other hand, these different stages are not dependent from the energy of marine action, as recently suggested by Lisco et al. 2017 for Sabellaria spinulosa bioconstructions, as the stasis coincides with the period of relatively low energy of storm waves. Probably, the stasis periods (spring and summer) are induced by the effect of mussel recruitment that starts before June and by the anthropic disturbance during the entire summer, since the Ostia Lido is one of the most popular beaches of the Latium coast. More ecological studies are needed to find a reliable origin for the decline periods of this bioconstruction. The model of the seasonal changes has been summarised in Fig. 16, where the main stages are recorded in the bioconstruction, also at a microscopic scale, as: (1) number of worm tubes; (2) relative abundance of small and large tubes; (3) actual range of the variability of tube diameters. 


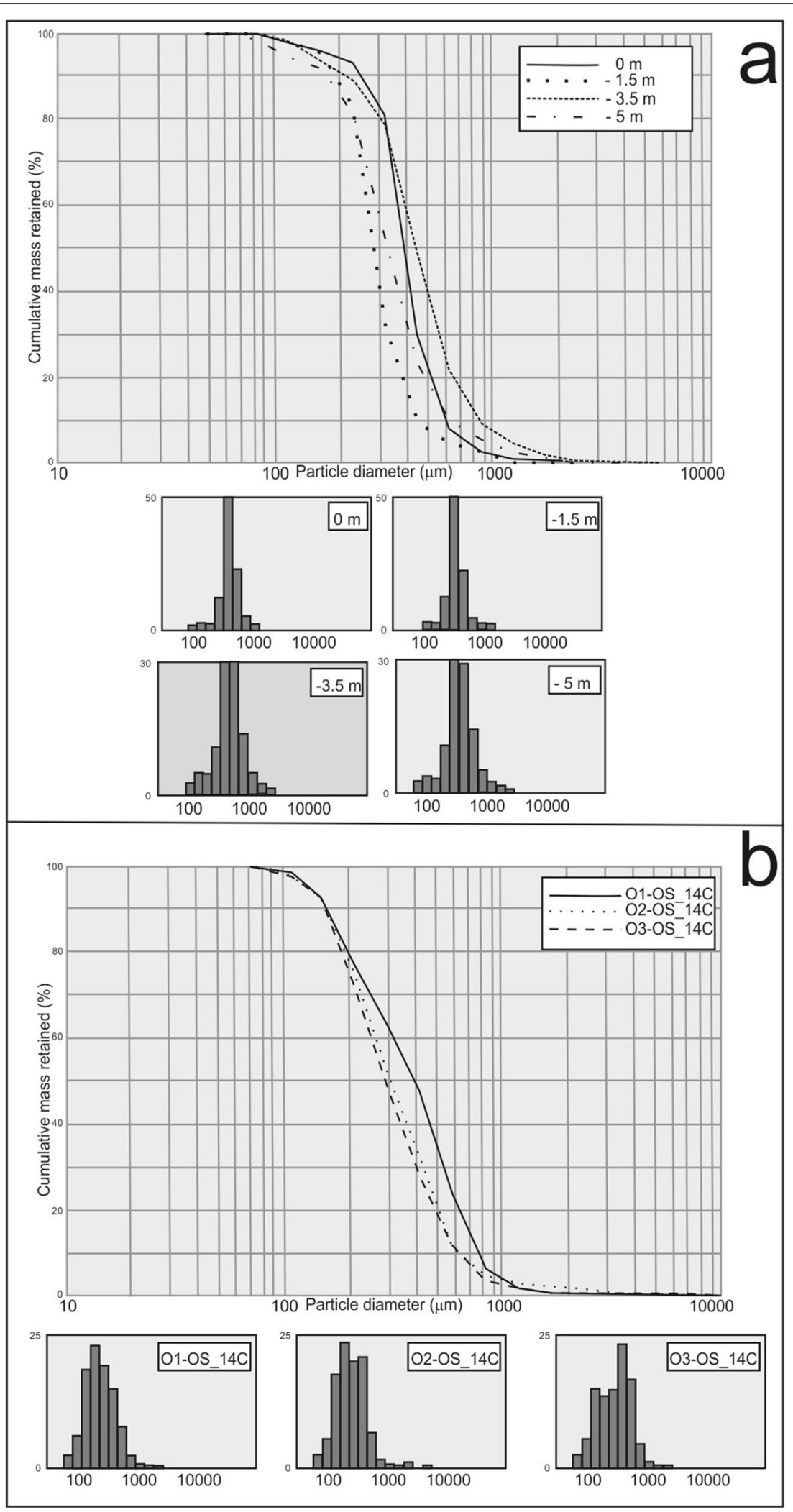

Fig. 11 Grain-size analysis results: (a) Beach sands (from beachface and shoreface environments). Different dotted lines represent samples coming from different water depths; (b) Cumulative curves for three disaggregated bioconstruction samples. Different dotted lines represent various samples. Note that only the statistical distributions of beach sands are always unimodal 


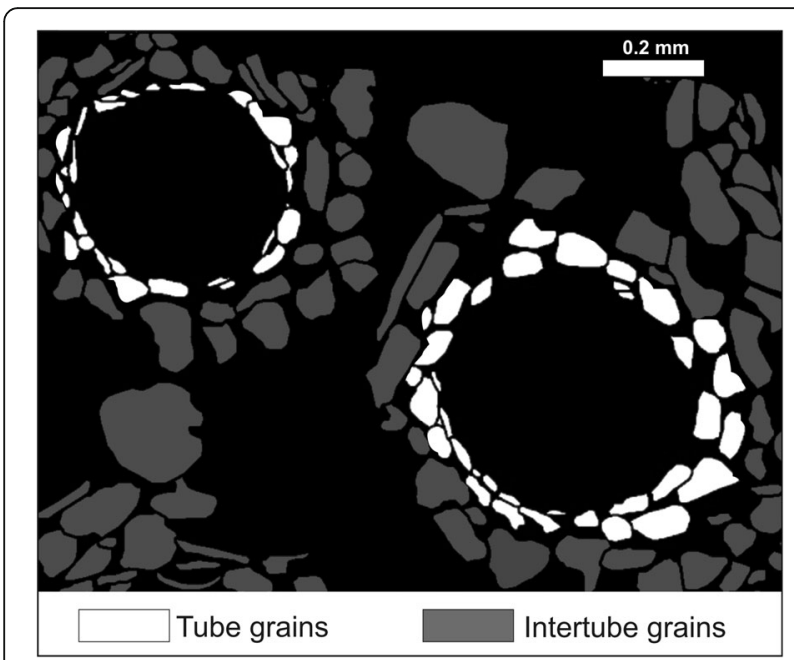

Fig. 12 The map imported in Imageje for the calculation of morphometric parameters. Sands have been separated into two classes: tube (white) and intertube (grey) grains

\subsection{Textural features of the Sabellaria alveolata bioconstruction \\ 5.2.1 Grain size}

As mentioned in the introduction, many authors have estimated the grain size of sands that are trapped by different taxa of worms to build their tubes (see different methods in Table 1). If sieving analyses are carried out on disaggregated fragments of the bioconstruction, the results will record the granulometric distribution of tube and intertube sediments. Carefully isolating single tubes before sieving analyses possibly helps to obtain more representative data for the actual grain size of sediments that the worm traps (Naylor and Viles 2000). Meanwhile, using the image analysis approach on thin sections and obtaining highresolution photos can help to calculate single grain-size distributions for the different tube and intertube sectors of the bioconstruction and help to compare them with the grain size of sands available in the beach sub- environments. This method also allows investigating those sediments trapped by small or young worms that could be the most abundant population in some seasons.

Table 3 shows the results of the granulometric distribution of sands coming from: (1) bioconstruction samples impregnated with resin (image analysis); (2) beach sub-environments; (3) disaggregated bioconstruction fragments (physical sieving analysis). In agreement with previous researches, our results show that Sabellaria alveolata seems to select sands on the basis of their grain sizes (see Gruet 1984). In particular, the worm seems to trap the finer fraction of the sands in the beachface and shoreface environments. This result is remarkable for the role of Sabellaria alveolata bioconstruction in the coastal protection. It is generally accepted that the worm reef forms physical barriers for the action of storm waves, tides and currents, and increases the cohesion in the soft sediment at sea-bottom (Fournier 2013). The abundance of relatively finegrained sediments in the bioconstruction structure shows that the Sabellaria alveolata bioconstructions are also important as temporary repository during the highenergy storm events of autumn and winter. The finegrained fraction is the first granulometric range that disappears in the retreating sandy beaches and typically recorded by negative Skewness values. Probably, during large storm-wave events, the worms trap the finegrained sands saved from the erosion and the transport toward the shelf or alongshore. These sands return to the beach during seasonal decline periods.

The result of grain-size analyses shows also that sands forming the tubes are more sorted than sands that occupy the intertube sectors of the bioconstruction even if these different parts of the bioconstruction seem to contain sands with the same fiftieth percentile $\left(D_{50}\right.$ tube $=$ $\mathrm{D}_{50}$ intertube). This result is related to the way in which each worm selects the grains to build its tube. The diameter of the particles that can be potentially inserted in

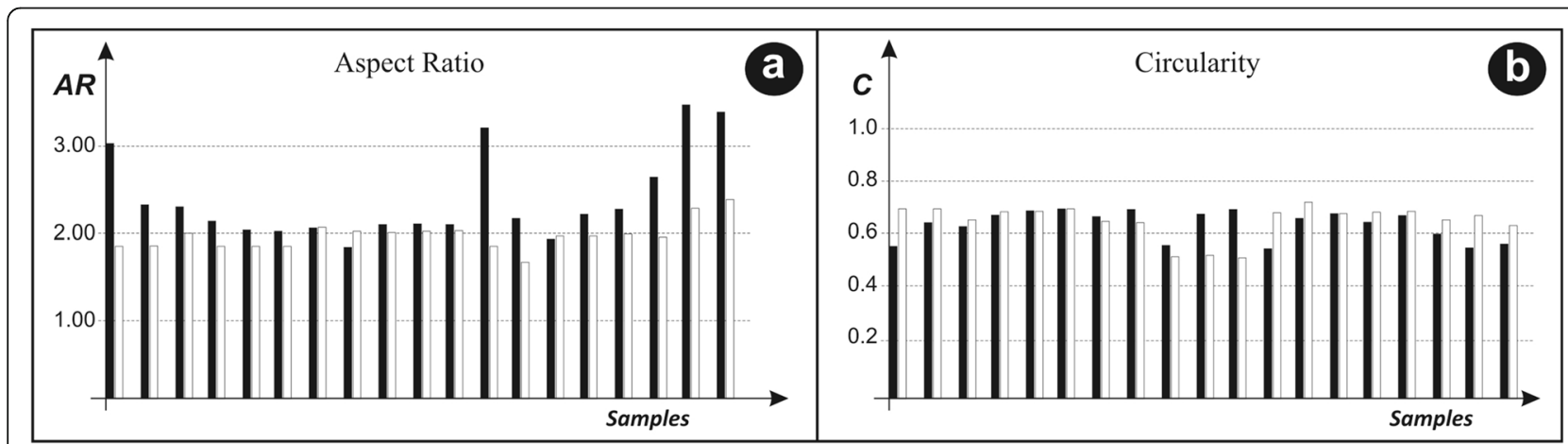

Fig. 13 Morphometric analysis results: (a) Aspect Ratio of grains in tube (black) and intertube (white); (b) Circularity of grains in tube (black) and intertube (white). Each column represents the mean value of more than 50 grains in tube and intertube sectors respectively. Grains of the tubes are more elongated, with higher Aspect Ratio and lower Circularity, than grains that are casually deposited between adjacent tubes (intertubes) 


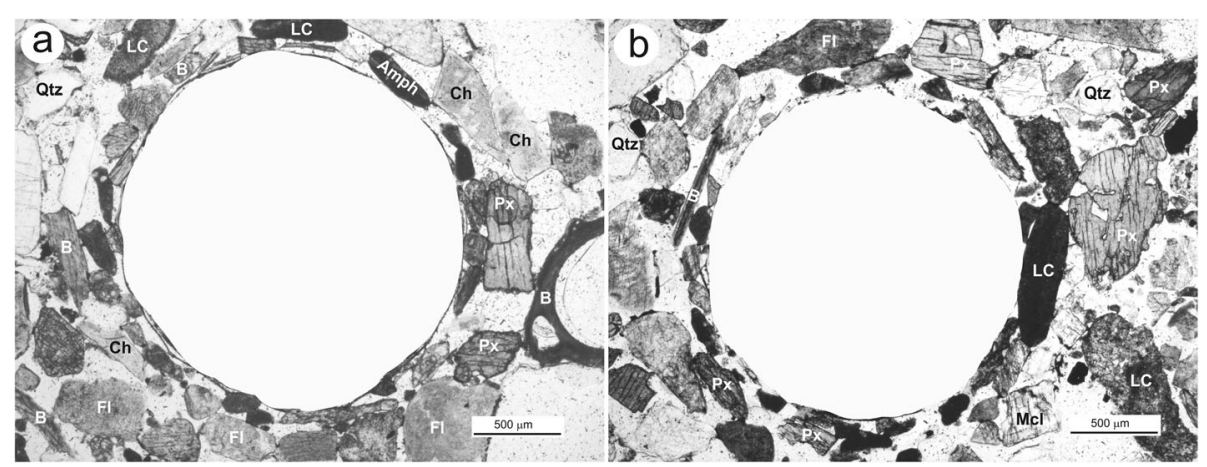

Fig. 14 Two cross-polarized light photos $(\mathbf{a}, \mathbf{b})$ showing the main compositional features of the sands trapped in the Sabellaria alveolata Bioconstruction. Amph Amphibole, B Carbonate bioclasts, Ch Chert, Fl Lithic fragments, LC Carbonate lithoclasts, Mcl Microcline, Px Pyroxene, Qtz Quartz

the tube bioconstruction is related to the size of the organ that physically traps the sands, as suggested by Gruet (1984). If the bioconstruction is characterized by worms of a specific age range, the trapped sands would be limited to a specific grain-size class. To prove this relationship in a quantitative way, a comparison between the diameters of the worm tube, which is selected dependently from its age, and the $D_{50}$ values of the tube sands has been performed. The correlation between these two measured parameters is linear/positive even if its correlation degree is low (Fig. 17), confirming the hypothesis of Gruet (1984).

\subsubsection{Grain shape}

The main morphometric parameters of the grains directly trapped by the worm are measured with an aim to quantitatively demonstrate, for the first time, that Sabellaria alveolata is able to select particles with some

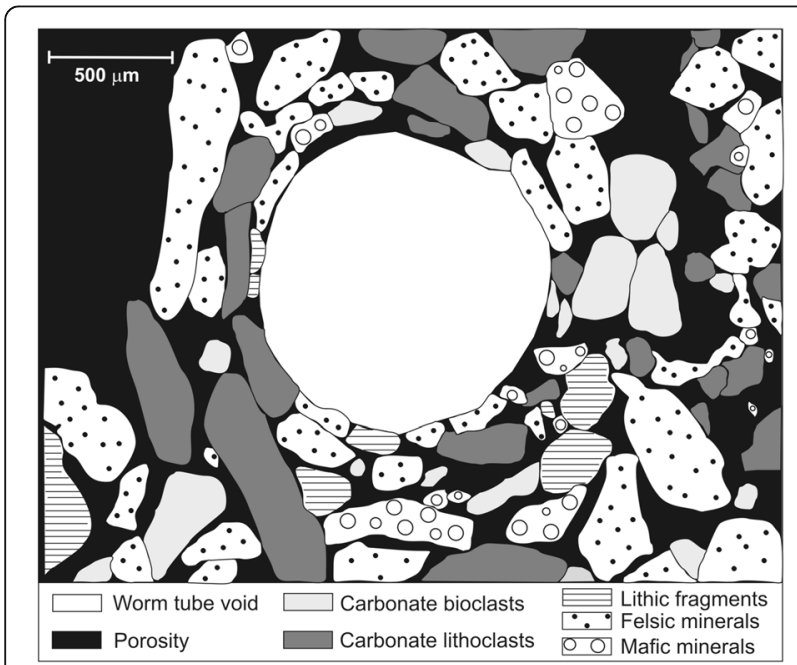

Fig. 15 An example of the compositional map of tube and intertube sectors in the Sabellaria alveolata bioconstruction particular coefficients of the grain shape, as suggested in many previous papers (see Fournier 2010 and references therein). Comparing grains of the tube and grains of the intertube sectors of the bioconstruction (Fig. 13) shows that Sabellaria alveolata actually prefers selecting elongated particles. These particles are often made up of bioclasts (foraminifera and molluscs). La Porta et al. (2006) suggested that bioclasts are very abundant in the tubes, since the shell fragments can be eroded and put in suspension in a very easy way during storm-wave events.

\subsubsection{Porosity}

The porosity of the Sabellaria alveolata bioconstruction is variable between $28 \%$ and $37 \%$. These values are low if compared with present-day carbonate

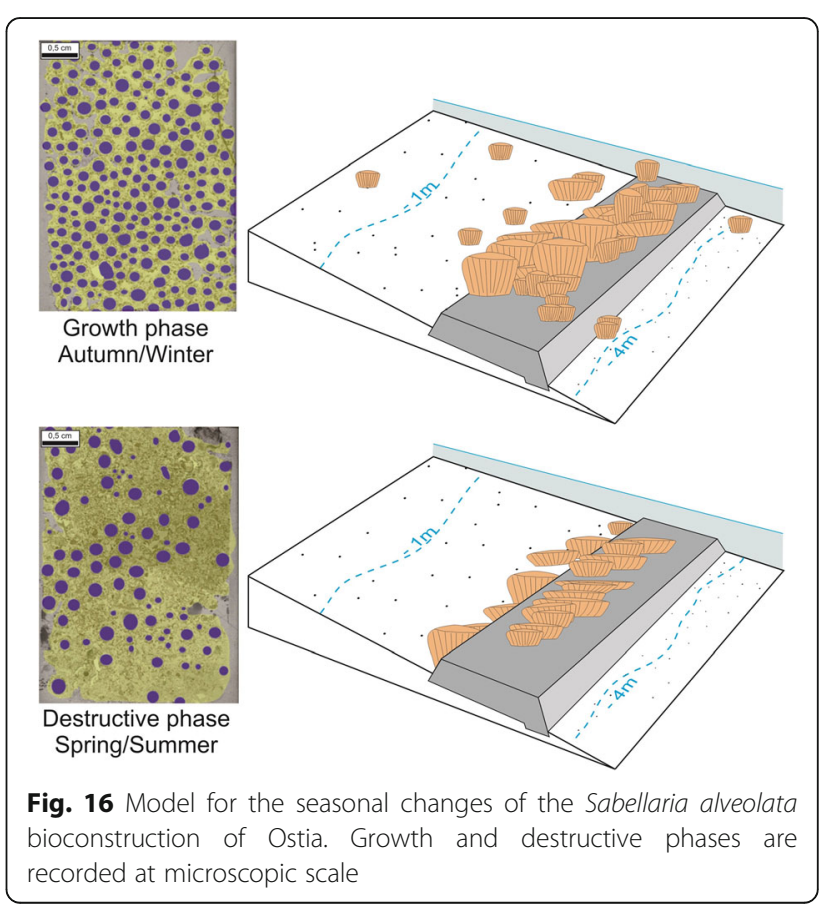


Table 3 The fiftieth percentile of the grain-size distribution of tube, intertube, beach and disaggregated bioconstruction sands are shown

\begin{tabular}{ll}
\hline Sand source & Grain size \\
\hline Tube and/or intertube & $\begin{array}{l}\text { About } 200 \mu \mathrm{m} \\
\left(D_{50} \text { tube }=D_{50} \text { intertube }\right)\end{array}$ \\
$\begin{array}{l}\text { Beach sub-environment } \\
\text { Bisaggregated } \\
\text { bioconstruction fragments } 311 \mu \mathrm{m} \text { and } 499 \mu \mathrm{m}\end{array}$ \\
\hline
\end{tabular}

bioconstructions which have porosity values variable between $40 \%$ and $70 \%$ (Ahr 2008). In the worm bioconstructions, the largest voids shape the interior of the tubes, after the death of the organism, but they could be filled by sands over time, during successive evolutive stages (Fig. 9). This kind of low porosity could guarantee a greater resistance of the worm bioconstruction in the absence of carbonate cement.

\subsection{Mineralogical features of the Sabellaria alveolata bioconstruction}

All samples can be defined as lithic arenites according to Folk (1974) and there are no differences between sands from the bioconstruction (tube and intertube) and sands of the surrounding shallow-marine environments. This result obviously implies that Sabellaria alveolata is not able to select grains on the basis of their mineralogical composition, as suggested by the literature data. At the same time, however, that is in apparent contrast with data showing the abundance of bioclasts for the construction of the tube. To explain these inconsistent data, a mineralogical classification that is more suitable for

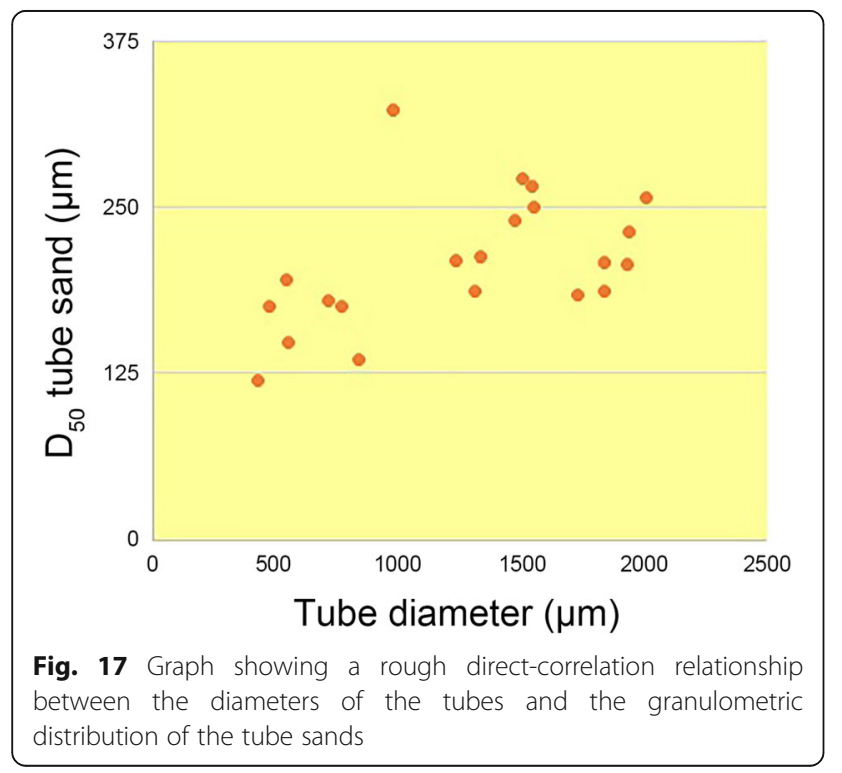

hybrid sands (Zuffa 1980) has been used. The felsic and mafic minerals and the lithic fragments were grouped in the NCE class (non-carbonate extrarenite class); the carbonate lithoclasts were grouped in the CE class (carbonate extrarenite class); and, the bioclasts were grouped in the CI class (carbonate intrarenite class). Fig. 18 shows the results of this classification. The sands have a low content in bioclasts and are mainly classified as siliciclastic hybrid sands or hybrid sands, among which, only one sample is classified as a calcilithic hybrid sand. Nevertheless, there are some slight differences of the content in bioclasts in tube, intertube, and beach sands. Beachface and shoreface contain a higher content of bioclasts compared with tube and intertube sectors of the bioconstruction. This data is not surprising, since not all bioclasts that are available in the shallow-marine environments can be trapped by the worm, as a result of the differences in bulk density, composition, shape, roughness, etc. Sands that form the tubes contain a larger number of bioclasts than in the intertubes. This data shows that the Sabellaria alveolata tubes contain grains having no specific composition, except for carbonate bioclasts that are trapped because their elongated morphology and low bulk density could result in a higher chance of being suspended during storm events.

\section{Conclusions}

The genus Sabellaria is a very common bioconstructor in temperate areas; its bioconstructions reach large dimensions along the coasts of the oceans and in the Mediterranean Sea. The peculiarity of these polychaetes is represented by the manner in which sand grains are agglomerated to build bioconstructions made up of

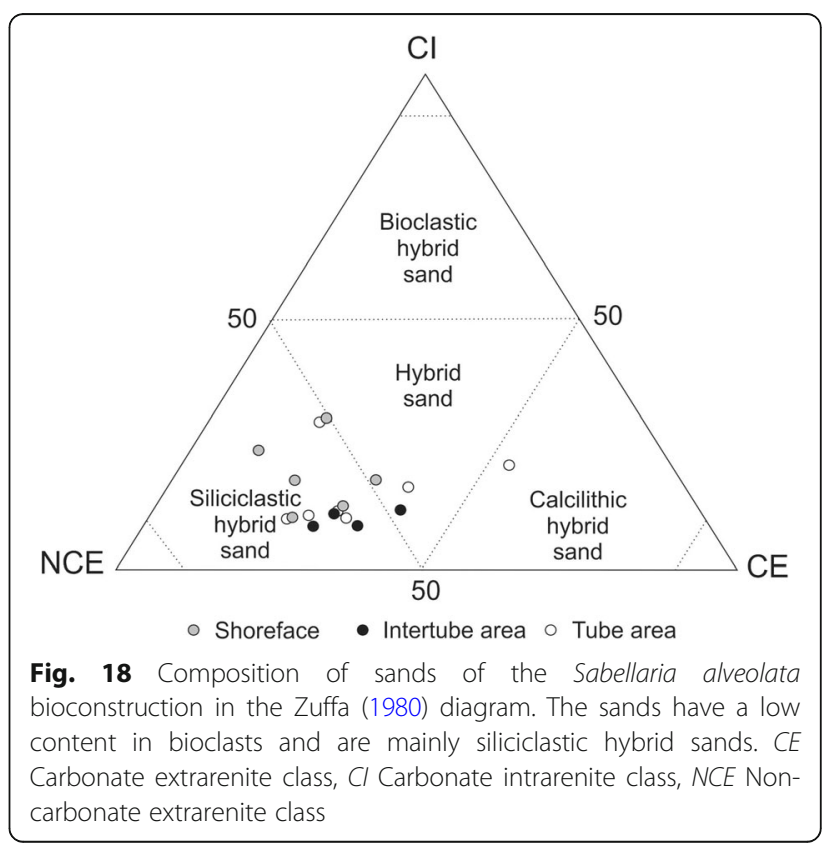


millions of centimetric tubes. Data and results of this study show that Sabellaria alveolata bioconstructions contain: (1) sands that are directly inserted by the worms in the tube framework and (2) sands that fill the spaces between adjacent tubes (intertube areas). Tube and intertube sands have more or less the same $D_{50}$ (about $200 \mathrm{~mm}$ ), but tube sands are well sorted, being selected by the worms and by their building organ, while intertube sands are poorly sorted, being casually deposited in the empty spaces. Nevertheless, both sectors have sands that are fine-grained if compared with sands of the surrounding beach sub-environments. By a mineralogical point of view, the Ostia worm bioconstruction holds sandy grains that have the same compositional features of beach sands; tubes show a slight increase in the bioclast content. This result seems to be confirmed by the morphometric analysis that proves a definite predominance of elongated grains in the worm tubes.

A clear relationship between the size/density of worm tubes and the seasonal variations has been established and compared with data coming from classical ecological procedures (scuba diving monitoring, Sabellaria larvae sampling, etc.) carried out in the same study area. At a microscopic scale, the bioconstruction growth phases (winter and autumn) are recorded by: (1) a high tube density; (2) a drastic decrease of tubes diameters; (3) a large variability of the tube diameters. The destructive phases (spring and summer) can be recognised by: (1) the low tube density; (2) an increase of tube diameters; (3) a low variability of tube diameters. These results show that the autumnal larval peak of Sabellaria alveolata, the vernal mussel recruitment, and the summer anthropogenic disturbances leave unmistakable traces in the sedimentary record of the worm tubes.

In conclusion, this study shows that the Sabellaria alveolata bioconstructions are fundamental for the coastal protection, representing a continuous and stable storage of fine-grained sands during their seasonal evolutionary stages. The monitored cyclic volume variations of the bioconstruction (described as areal/thickness changes) and the calculation of its total porosity (relatively low if compared with carbonate reefs) show that the Sabellaria alveolata bioconstructions act as nourishment agents, storing and furnishing enormous quantities of sediment that can be redistributed in the coastal subenvironments by the action of storm waves, tides and currents.

\section{Abbreviations}

AR: Aspect Ratio; C: Circularity; CE: Carbonate extrarenite; Cl: Carbonate intrarenite; $D_{50}$ : Fiftieth percentile of the grain-size distribution; n: Porosity; NCE: Non-carbonate extrarenite; Sk: Skewness; $V_{T}$ : Sample volume; $V_{V}$ : Pore volume

\section{Acknowledgements}

The authors thank Prof. Zeng-Zhao Feng, Prof. Ian D. Somerville, Ms. Yuan Wang and two anonymous reviewers for comments that greatly improved the manuscript.

\section{Authors' contributions}

All the Authors have actively participated to the preparation of the final proof of the manuscript. The geological data have been collected and interpreted by S.N. Lisco and M. Moretti. Petrographic analysis has been carried out by S.N. Lisco, P. Acquafredda, S. Gallicchio, and L. Sabato. S. Gallicchio and L. Sabato have realized the geological framing of the study area. Biological data have been collected by A. Bonifazi, F. Cardone, and M.F. Gravina. The interpretation of the biological data has been carried out by A. Bonifazi, F. Cardone, M.F. Gravina, G. Corriero, and C. Pierri. The integration of geophysical and biological data has been carried out by S.N. Lisco, M. Moretti, and G. Corriero.

\section{Funding}

The authors declare that the data reported here were obtained with research financed by the universities involved.

Availability of data and materials

The datasets analysed during the current study are available from the corresponding author on reasonable request.

\section{Competing interests}

The authors declare that they have no competing interests.

\section{Author details}

${ }^{1}$ Dipartimento di Scienze della Terra e Geoambientali, Università degli Studi di Bari, 70124 Bari, Italy. ${ }^{2}$ Dipartimento di Biologia, Università degli Studi di Bari, 70124 Bari, Italy. ${ }^{3}$ Dipartimento di Biologia, Università di Roma "Tor Vergata", 00133 Rome, Italy.

Received: 21 May 2019 Accepted: 11 November 2019

Published online: 13 January 2020

\section{References}

Achary, G.P.K. 1969. Sabellariids as associates of other invertebrates and their role in the formation of benthic animal communities. Journal of the Marine Biological Association of India 11 (1-2): 198-202.

Achary, G.P.K. 1974. Polychaetes of the family Sabellariidae with special reference to their intertidal habitat. Proceedings of the Indian National Science Academy 38: 442-455.

Ahr, W.M. 2008. Geology of carbonate reservoirs: The identification, description, and characterization of hydrocarbon reservoirs in carbonate rocks, 278. Hoboken, NJ: Wiley and Sons, Inc.

Bellotti, P., F.L. Chiocci, S. Milli, P. Tortora, and P. Valeri. 1994. Sequence stratigraphy and depositional setting in the Tiber delta: Integration of high-resolution seismics, well logs, and archeological data. Journal of Sedimentary Research B64: 416-432.

Bellotti, P., S. Milli, P. Tortora, and P. Valeri. 1997. Physical stratigraphy and sedimentology of the late Pleistocene-Holocene Tiber Delta depositional sequence. Sedimentology 42: 617-634.

Bonifazi, A., M. Lezzi, D. Ventura, S. Lisco, F. Cardone, and M.F. Gravina. 2019. Macrofaunal biodiversity associated with different developmental phases of a threatened Mediterranean Sabellaria alveolata (Linnaeus, 1767) reef. Marine Environmental Research 145: 97-111.

Braithwaite, C.J.R., R.J. Robinson, and G. Jones. 2006. Sabellarids: A hidden danger or an aid to subsea pipelines? Quarterly Journal of Engineering Geology and Hydrogeology 39: 259-265.

Capelli, G., R. Mazza, and C. Papiccio. 2007. Intrusione salina nel Delta del Fiume Tevere. Geologia, idrologia e idrogeologia del settore romano della piana costiera. Giornale di Geologia Applicata 5: 13-28.

Delbono, I., C.N. Bianchi, and C. Carla Morri. 2003. Le biocostruzioni di Sabellaria alveolata come indicatori ambientali: area costiera fra Chiavari e Sestri Levante. In Studi per la creazione di strumenti di gestione costiera, ed. O. Ferretti, 130-140. Genoa: Golfo del Tigullio.

Desroy, N., S. Dubois, J. Fournier, L. Ricquiers, P. Le Mao, L. Guérin, D. Gerla, M. Rougerie, and A. Legendre. 2011. Conservation status of Sabellaria 
alveolata (L.) (Polychaeta: Sabellariidae) reefs in the Mont-saint-Michel bay. Aquatic Conservation-Marine and Freshwater Ecosystems 21: 462-471.

Dubois, S., L. Barillé, and C. Retière. 2003. Efficiency of particle retention and clearance rate in the polychaete Sabellaria alveolata L. Comptes Rendus Biologies 326: 413-421.

Dubois, S., T. Comtet, C. Retière, and E. Thiébaut. 2007. Distribution and retention of Sabellaria alveolata larvae (Polychaeta: Sabellariidae) in the bay of Mont Saint Michel, France. Marine Ecology Progress Series 346: 243-254.

Ekdale, A.A., and D.W. Lewis. 1993. Sabellariid reefs in Ruby Bay, New Zealand, a modern analogue of Skolithos "piperock" that is not produced by burrowing activity. PALAIOS 8: 614-620.

Ferrante, A., L. Franco, and S. Boer. 1993. Modelling and monitoring of a perched beach at Lido di Ostia. Proceedings of the 23rd International Conference of Coastal Engineering (ICCE) 3: 3305-3318.

Folk, R.L. 1974. Petrology of sedimentary rocks, 170 pp. Austin: Hemphill Publishing Company.

Fournier, J. 2010. Bibliography of coastal worm-reef and tube worm species of the world (1950-2010), 43 pp. Dinard: CNRS/MNHN.

Fournier, J. 2013. Bioconstructions d'annélides polychètes. In Mémoire d'Habilitation à Diriger des Recherches, Volume 2. Synthese scientifique, 171 pp. Brest: Université de Bretagne Occidentale, Institut Universitaire Européen de la Mer, CNRS.

Franco, L., M. Di Risio, C. Riccardi, P. Scaloni, and M. Conti. 2004. Monitoraggio del ripascimento protetto con barriera sommersa nella spiaggia di Ostia Centro. Studi Costieri 8: 3-16.

Giraudi, C.E. 2004. Evoluzione tardo-Olocenica del Delta del Tevere, ॥ Quaternario. Italian Journal of Quaternary Sciences 17: 477-492.

Gravina, M., G. Chimienti, C. Longo, G. Corriero, S. Lisco, M. Moretti, F. Cardone, C. Nonnis Marzano, M. Bertrandino, A. Giangrande, V. Moretti, and A. Bonifazi. 2018. Sabellaria spinulosa (Annelida, Polychaeta) reefs in the Mediterranean Sea: Habitat mapping, dynamics and associated fauna for conservation management. Estuarine, Coastal and Shelf Science 200: 248-257.

Gruet, Y. 1984. Granulometric evolution of the sand tube in relation to growth of the polychaete annelid Sabellaria alveolata (Linné) (Sabellariidae). Ophelia 23: 181-193.

Gruet, Y. 1986. Spatio-temporal changes of Sabellarian reefs built by the sedentary Polychaete Sabellaria alveolata (LINNE). Marine Ecology. Pubblicazioni della Stazione Zoologica di Napoli 73: 303-319.

Gruet, Y., and P. Lassus. 1983. Contribution à l'étude de la biologie reproductive d'une population naturelle de l'annélide polychète Sabellaria alveolata (Linné). Annales de I'Institute Oceanographique 59: 127-140.

Gruet, Y., J. Vovelle, and M. Grasset. 1987. Composante biominerale du ciment du tube chez Sabellaria alveolata (L.) Annelide Polychete. Canadian Journal of Zoology 65: 837-842.

Gubbay, S. 2007. Defining and managing Sabellaria spinulosa reefs: Report of an inter-agency workshop 1-2 may, 2007. JNCC report N. 405: 22 pp.

Holt, T.J., E.I. Rees, S.J. Hawkins, and R. Seed. 1998. Biogenic reefs (volume IX). In An overview of dynamic and sensitivity characteristics for conservation management of marine SACS, 170 pp. Oban: Scottish Association for Marine Science (UK Marine SACs Project).

La Porta, B., and L. Nicoletti. 2009. Sabellaria alveolata (Linnaeus) reefs in the Central Tyrrhenian Sea (Italy) and associated polychaete fauna. Proceedings of the 9th International Polychaete Conference, Zoosymposia 2: 527-536.

La Porta, B., L. Lattanzi, P. La Valle, M. Panfili, M. Targusi, and L. Nicoletti. 2006. Studio del popolamento a Policheti di fondi mobili del Tirreno Centrale. Biologia Marina Mediterranea 13: 188-189.

Lisco, S., M. Moretti, V. Moretti, F. Cardone, C. Longo, and G. Corriero. 2017. Sedimentological features of Sabellaria spinulosa bioconstructions. Marine and Petroleum Geology 87: 203-212.

Milli, S., C. D'Ambrogi, P. Bellotti, G. Calderoni, M.G. Carboni, A. Celant, L. Di Bella, F. Di Rita, V. Frezza, D. Magri, R.M. Pichezzi, and V. Ricci. 2013. The transition from wave-dominated estuary to wave-dominated delta: The Late Quaternary stratigraphic architecture of Tiber River deltaic succession (Italy). Sedimentary Geology 284 (285): 159-180.
Molinier, R., and J. Picard. 1953. Notes biologiques à propos d'un voyage d'étude sur les côtes de Sicile. Masson. Annales de l'Institut Oceanographique 28 (4): 163-188.

Multer, H.G., and J.D. Milliman. 1967. Geological aspects of Sabellarian reefs, southeastern Florida. Bulletin of Marine Science 17: 257-267.

Naylor, L.A., and H.A. Viles. 2000. A temperate reef builder: An evaluation of the growth, morphology and composition of Sabellaria alveolata (L.) colonies on carbonate platforms in South Wales. In Carbonate platform systems: Components and interactions, ed. E. Insalaco, P.W. Skelton, and T.J. Palmer, vol. 178, 9-19. London: Geological Society, Special Publications.

Nealson, K., and W.A. Ghiorse. 2001. Geobiology: Exploring the interface between the biosphere and the geosphere, $23 \mathrm{pp}$. Washington, DC: American Academy of Microbiology.

Nicoletti, L., L. Lattanzi, B. La Porta, P. La Valle, M.C. Gambi, P. Tomassetti, P. Tucci, and C. Chimenz Gusso. 2001. Sabellaria reefs from the Latium coast (Central Tyrrhenian Sea). Biologia Marina Mediterranea 8 (1): 252-258.

Pandolfi, J.M., D. Ross Robertson, and D.W. Kirtley. 1998. Roles for worms in reef-building. Coral Reefs 17: 120.

Poppe, L.J., A.H. Eliason, JJ. Fredericks, R.R. Rendigs, D. Blackwood, and C.F. Polloni. 2000. Grain-size analysis of marine sediments e methodology and data processing. In U.S.G.S. East-coast Sediment Analysis: Procedures, Database, and Georeferenced Displays, ed. L.J. Poppe, M.E. Hastings, A.H. Eliason, J.J. Fredericks, R.R. Rendigs, and D.S. Blackwood. Woods Hole, MA: U. S. Geological Survey U.S. Geological Survey open file report 00-358.

Posey, M.H., A.M. Pregnall, and R.A. Graham. 1984. A brief description of a subtidal Sabellariid (Polychaeta) reef on the southern Oregon coast. Pacific Science 38: 28-33.

Praturlon, A. 2008. II vecchio e il nuovo delta del Tevere (Fiumicino e Ostia, la spiaggia e il Porto di Roma). In: Funiciello, R., A. Praturlon, and G. Giordano. (Eds.). The geology of Rome. From the historical center to the outskirts. Memorie Descrittive della Carta geologica d'ttalia 80: 221-235.

Ribero, L., and G. Polgar. 2012. The polychaete reefs of Jeram, Selangor. In Mangrove and coastal environment of Selangor, Malaysia, ed. A. Sasekumar and V.C. Chon, 87-95. Kuala Lumpur: University of Malaya.

Sparla, M.P., G. D'Anna, and S. Riggio. 1992. Notes on the development and invertebrate colonization of Sabellaria alveolata reefs in N/W Sicily. Rapport Commission International Mer Méditerranée 33: 53.

Taramelli Rivosecchi, E. 1961. Osservazioni sulle biocenosi del banco a Sabellaria di Lavinio. Rendiconti Accademia Nazionale delle scienze detta dei XL. Memoire di Matematica IV 12: 1-11.

Wust, R.A.J. 2011. Binding organisms. In Encyclopedia of modern coral reefs: Structure, form and process. Encyclopedia of Earth Science, ed. D. Hopley, 136-139. Dordrecht: Springer.

Zale, A.V., and S.G. Merrifield. 1989. Species profiles: life histories and environmental requirements of coastal fishes and invertebrates (South Florida) ladyfish and tarpon. U.S. fish Wildlife Service Biology Report 82 (11. 104). U.S. Army Corps of Engineers Report TR EL82-4: 17.

Zuffa, G.G. 1980. Hybrid arenites: Their composition and classification Journal of Sedimentary Petrology 50: 21-29.

\section{Publisher's Note}

Springer Nature remains neutral with regard to jurisdictional claims in published maps and institutional affiliations. 